\title{
Asociación de cultivos, alternativa para el desarrollo de una agricultura sustentable
}

\author{
Crop association, alternative for sustainable agriculture \\ development
}

\author{
Christian Vicente Tamayo Ortiz ${ }^{1}$ Julio Cesar Alegre Orihuela ${ }^{2}$
}

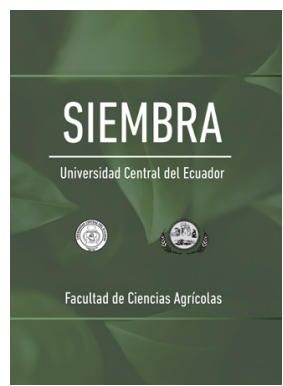

\footnotetext{
${ }^{1}$ Universidad Central del Ecuador, Facultad de Ciencias Agrícolas, Jerónimo Leiton y Gato Sobral, Ciudadela Universitaria, 170521. Quito, Ecuador.

凶cvtamayo@uce.edu.ec

(D. https://orcid.org/0000-0002-4433-8594

${ }^{2}$ Universidad Agraria La Molina, Facultad de Agronomía, Departamento de Suelos. Lima, Perú.

$\otimes$ julitoalegre@gmail.com

Q https://orcid.org/0000-0002-7282-045X

*Autor de correspondencia:

cvtamayo@uce.edu.ec
}

\begin{abstract}
Resumen
Este estudio, basado en una revisión bibliográfica, generó un documento que está orientado a evidenciar la importancia de la asociación de cultivos para una agricultura sustentable. La siembra de especies asociadas es realizada desde épocas antiguas en América Latina y, en la actualidad, todavía es posible identificarla en diferentes territorios con predominio de una agricultura campesina. Esta lógica de valorización de la tierra puede ser aplicada con diversos arreglos, sobre la base de cultivos de ciclo corto, perenne, especies hortofrutícolas, pasturas, árboles e incluso la incorporación de crianza de animales mayores. Los principales beneficios de estos sistemas de uso de los suelos en comparación con los sistemas de monocultivo están relacionados con una mejor eficiencia del uso de recursos naturales (tierra y agua), mayor rendimiento de producto, incremento de ingresos, mitigación del cambio climático (por la mayor capacidad de almacenamiento de carbono), reducción de las poblaciones plaga y patógenos, fomento del control biológico, aumento de la diversidad poblacional de macro y microorganismos benéficos, así como el mejoramiento de la fertilidad del suelo. A pesar de que la mayoría de resultados demuestra las ventajas de esta innovación, se destaca la necesidad de generar resultados integrales que refuercen el planeamiento de esta propuesta como una alternativa de producción de alimentos altamente viable.
\end{abstract}

Palabras clave: policultivos, biodiversidad, cambio climático, sistemas agroforestales, agroecología.
Abstract
This study based on a literature review generated a document that is ori- ented to demonstrate the importance of crop association for sustainable agriculture. The planting of associated species has been done since an- cient times in Latin America and today, it is still possible to identify it in different territories with a predominance of peasant agriculture. This logic of land valorization can be applied with different arrangements based on short-cycle crops, perennial crops, horticultural species, pastures, trees and even the incorporation of livestock. The main benefits of these land use systems compared to monoculture systems are related to improved efficiency of natural resource use (land and water), higher product yields, 
increased income, climate change mitigation (due to increased carbon storage capacity), reduction of pest and pathogen populations, promotion of biological control, increased population diversity of beneficial macro and microorganisms as well as improved soil fertility. Although most of the results demonstrate the advantages of this innovation, the need to generate integral results that reinforce the planning of this proposal as a highly viable food production alternative is highlighted.

Keywords: polycultures, biodiversity, climate change, agroforestry systems, agroecology.

\section{Introducción}

En la actualidad, la producción agropecuaria se sustenta en un modelo que simplifica los agroecosistemas con monocultivos; a pesar de que la biodiversidad es necesaria para la seguridad alimentaria de la población (Organización de las Naciones Unidas para la Alimentación y la Agricultura [FAO], 2018). La consolidación de este enfoque reduccionista y altamente dependiente de insumos químicos ha contribuido al deterioro del suelo, contaminación del agua e incluso a la salud humana (Sarandón, 2002). Para enfrentar esta problemática, es vital una transición de una orientación que privilegia únicamente el incremento de ganancias, a una visión que también priorice el uso eficiente de los recursos naturales, calidad de vida de las actuales y futuras generaciones, y que se articule a las condiciones y culturas locales. La asociación de cultivos constituye una alternativa para este propósito por poseer varias ventajas frente a sistemas basados en una sola especie. Varios estudios han demostrado las bondades de la diversidad en los campos agrícola, en relación con el incremento de la productividad vegetal (Ebel et al., 2017; Molina-Anzures et al., 2016) y animal (Rivera et al., 2015), mejoramiento de ingresos (Aguirre, 2017; Rezende et al., 2009), atenuación del cambio climático (Alegre, 2017; Palm et al., 2002), optimización del agua (Chamorro Viveros y Rey, 2017; Morales-Rosales et al., 2006), incremento de fertilidad del suelo (Navas Panadero et al., 2020; Vera, 2017) y bienestar familiar (Vásquez González et al., 2018). A pesar de existir un avance significativo en el campo de la investigación en cultivos múltiples, es necesario evidenciar las bondades de este tipo de innovación de manera integral; así como también, los principales tipos de arreglos que se pueden identificar en el sector rural. Por este motivo, la presente revisión bibliográfica tuvo como objetivo evidenciar la importancia de la asociación de especies en aspectos relacionados con la agricultura sustentable.

\section{Metodología}

El documento se sustenta en el análisis de artículos científicos de revistas indexadas y tesis de posgrado; además de libros y publicaciones institucionales que abordan teóricamente la temática analizada, presentan resultados de investigaciones y brindan orientaciones de política pública relacionada con el desarrollo sostenible. Para la búsqueda de información se empleó palabras clave como: policultivos, consorcio de cultivos, asociación de especies, sistemas productivos, sistemas agroforestales y sistemas silvopastoriles, tomando en cuenta la revisión de documentos en idiomas español, inglés y portugués. Debido a la existencia de varios trabajos con ese léxico fue necesario realizar una selección y análisis de textos con base en la siguiente estrategia: (i) selección de información publicada a partir del año 2000; (ii) análisis del título, que debía contener las palabras clave o, en su defecto, dar indicios de evidenciar la importancia de especies asociadas o comparación con monocultivos; (iii) revisión del resumen para identificar que efectivamente proporcione información relevante sobre los efectos de la siembra en consorcio; y (iv) selección y análisis de las investigaciones que se enmarquen principalmente en las dinámicas productivas desarrolladas en América Latina y el Caribe. Con base en el objetivo planteado se revisó un total de 88 documentos, entre artículos científicos, tesis doctorales, tesis de maestría, libros de carácter teórico y publicaciones relacionadas con políticas públicas y desarrollo sostenible.

A fin de contrastar los efectos de la siembra en asocio frente al monocultivo, se generaron tablas y figuras sobre la base de la información obtenida. Para evidenciar las diferencias en las variables de comparación se empleó la siguiente nomenclatura: (i) signo positivo «+» para casos de respuesta significativa y favorable para la asociación; (ii) signo negativo «-» que muestra un resultado desfavorable para el asocio y ventaja para el unicultivo; y (iii) signo igual «=», sin diferencia significativa entre ambos. A fin de no sobrecargar las tablas y figuras con los nombres científicos de cultivos que han sido objeto de estudio, esta información se presenta en Anexo. 


\section{Resultados y Discusión}

\subsection{Los cultivos asociados}

\subsubsection{Origen y evolución}

La asociación de cultivos «son sistemas complejos en los cuales dos o más especies vegetales se plantan con suficiente proximidad espacial para dar como resultado una competencia o una complementación» (Vandermeer, 1989, citado en Altieri, 2002, p. 50). Además, tienen la característica de estar sembrados en una misma área o superficie de terreno durante parte o todo su ciclo (Sarandón y Labrador, 2002). Su composición puede variar en el transcurso del tiempo, en función del período de cosecha o valoración de cada componente cultivado. Al implementar su siembra, pueden identificarse combinaciones simples (basadas en dos cultivares) hasta asociaciones de mayor complejidad, donde pueden coexistir más de doce especies (Liebman, 1999).

Combinar temporal o espacialmente diversos tipos de plantas es una práctica muy antigua y está estrechamente relacionada con la historia de las civilizaciones (Francis, 1986, citado en Sarandón y Labrador, 2002, p.190). En América Latina, esta lógica de siembra fue implementada en diversas regiones desde épocas prehispánicas, con el fin de disponer de una alimentación equilibrada y reducir el riesgo de obtener malas cosechas (Gómez Betancur et al., 2018; Mazoyer y Roudart, 2006); sin embargo, comienza a tener un quebranto por los procesos de cambio en la valorización del medio originado por la conquista española (Martínez Martín y Manrique Corredor, 2014) y su declive se profundiza con la expansión del modelo de la revolución verde, en las décadas de 1950-1970, que consolida al monocultivo como principal estrategia de generación de alimentos (Sarandón, 2002). En efecto, el uso de nuevas variedades dependientes de un paquete tecnológico (fertilización y control de plagas) fueron poco compatibles a la combinación con otras especies vegetales e influyeron en el progresivo abandono de asociaciones tradicionales en áreas campesinas (Le Gall, 2007; Ochoa Lozano, 2018; Ordoñez-Jurado et al., 2018).

A pesar de que en los últimos siglos esta práctica ha registrado una considerable disminución en el campo (Francis, 1986, citado por Sarandón y Labrador, 2002); en la actualidad, es posible identificar diversos tipos de arreglos en territorios con predominio de agricultura campesina (Caycho-Ronco et al., 2009; Ochoa Lozano, 2018; Peralta, 2016; Vásquez González et al., 2018). Además, con la importancia creciente de garantizar el acceso de alimentos sanos y nutritivos a la población, considerando el cuidado del ambiente (FAO et al., 2017; Organización Internacional del trabajo [OIT], 2017), esta estrategia recobra su importancia por estar asociada al cultivo de una amplia diversidad de especies y plantas herbáceas espontáneas comestibles (Vásquez González et al., 2018) y brindar una dieta más variada a los productores durante todo el año (Ochoa Lozano, 2018; Vásquez González et al., 2018).

\subsubsection{Principales arreglos en base a la asociación de cultivos}

(i) Asociaciones en sistemas agrícolas

\section{- $\quad$ Combinaciones en base a cultivos de ciclo corto}

Uno de los sistemas insignia del cultivo múltiple en esta categoría es la milpa, implementada desde épocas prehispánicas en regiones mesoamericanas (Vásquez González et al., 2018) y conformada principalmente por maíz (Zea mays), fréjol (Phaseolus vulgaris) y calabaza (Curcubita pepo) (Ebel et al., 2017); sin embargo, puede integrar muchas otras especies cultivadas y espontáneas (Aguilar et al., 2003).

En zonas andinas de Perú y Bolivia es frecuente cultivar papa (Solanum tuberosum) combinando variedades nativas (diversidad intraespecífica), o en asocio con otros cultivos (diversidad interespecífica), con el propósito de manejar riesgos climáticos y conservar la biodiversidad (Caycho-Ronco et al., 2009) (Figura 1). También en áreas campesinas de Cotacachi y Saraguro en Ecuador, es habitual la mezcla de variedades de fréjol en asocio o intercalamiento con maíz, tradicionalmente conocido como chakra o allpa, a fin de disminuir la propagación de plagas, enfermedades y generar alimentos en diferentes temporadas (Ochoa Lozano, 2018). Además, la siembra de quinua (Chenopodium quinoa) y chocho (Lupinus mutabilis) asociados o intercalados con fréjol, maíz o vicia (Vicia sp.) son implementados en pequeñas superficies (menores a una hectárea) por campesinos en varias localidades de Ecuador (Jacobsen y Sherwood, 2002; Peralta, 2016). 


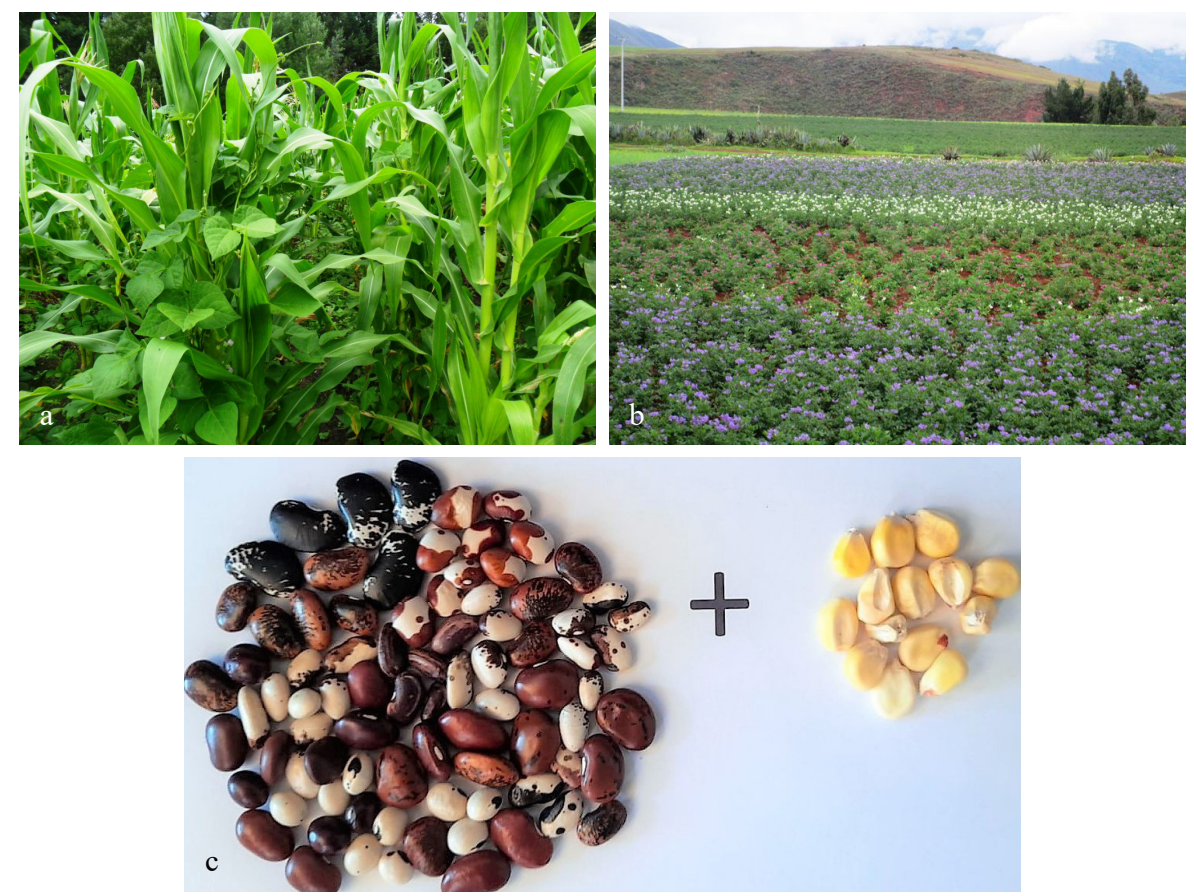

Figura 1. Asociación con cultivos de ciclo corto: a. Ecuador-valle de Tumbaco, b. Perú-Cusco, c. Ecuador-Cotacachi. Figure 1. Association with short-cycle crops: a. Ecuador-Tumbaco valley, b. Peru-Cusco, c. Ecuador-Cotacachi.

\section{Combinaciones empleando especies horticolas}

La combinación de especies hortícolas tiene un fuerte impulso en diversos sistemas productivos caracterizados como agroecológicos (Figura 2). Los arreglos implementados se basan en la siembra de varias especies mediante mezclas, rotaciones, intercalamientos y/o cultivos en franjas (Loyola Illescas, 2016; Silva-Laya et al., 2016). Además, es frecuente el establecimiento de barreras vivas a fin de impulsar efectos repelentes contra insectos y control de la erosión (Silva-Laya et al., 2016).
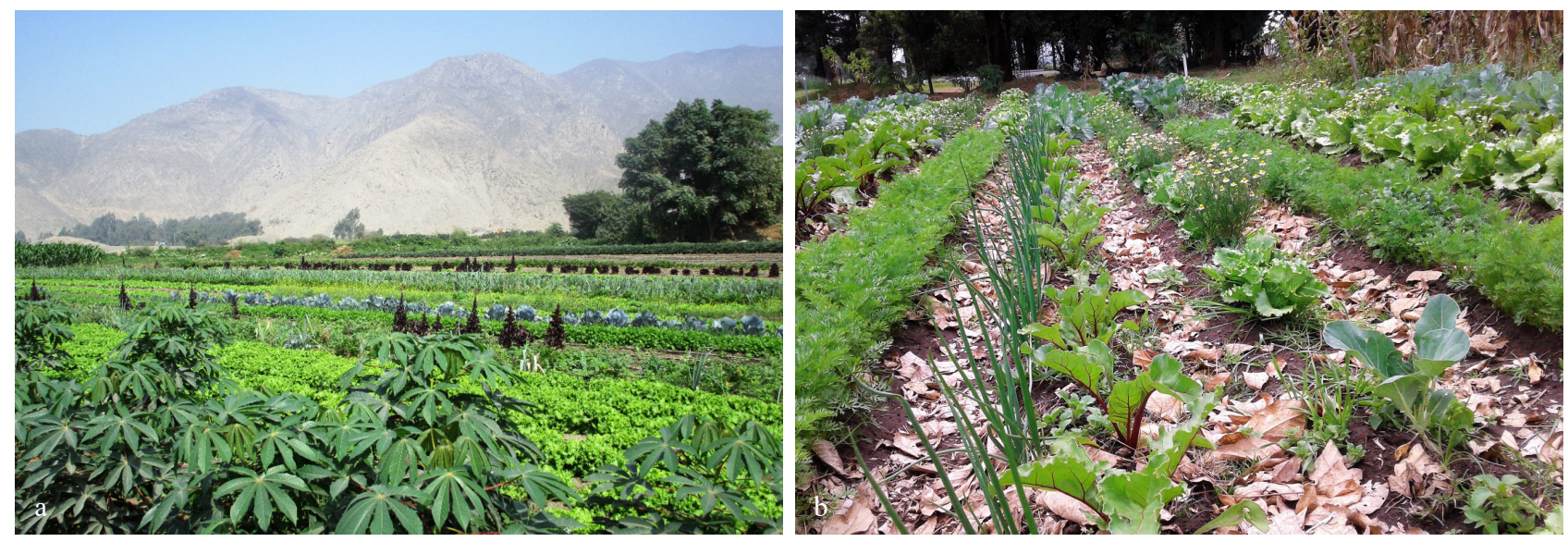

Figura 2. Asociación de cultivos con especies hortícolas: a. Perú-valle del Lurín, b. Ecuador- valle de Tumbaco. Figure 2. Crop association with horticultural species: a. Peru-Lurin valley, b. Ecuador-Tumbaco valley.

\section{- $\quad$ Combinaciones con cultivos perennes o semiperennes}

La combinación de cultivos perennes o semiperennes, orientados a mercados locales e incluso internacionales, es una práctica tradicional en sistemas productivos campesinos de áreas tropicales. Arreglos con base en el cacao (Theobroma cacao), café (Coffea arabica) o plátano (Musa ABB), en asocio con otros cultivos, se pueden identificar en predios de pequeños productores de Colombia, Ecuador y Perú (Jadán et al., 2012; Maignan y Nicolalde, 2007; Marín et al., 2016; Ordóñez Jurado et al., 2018). 

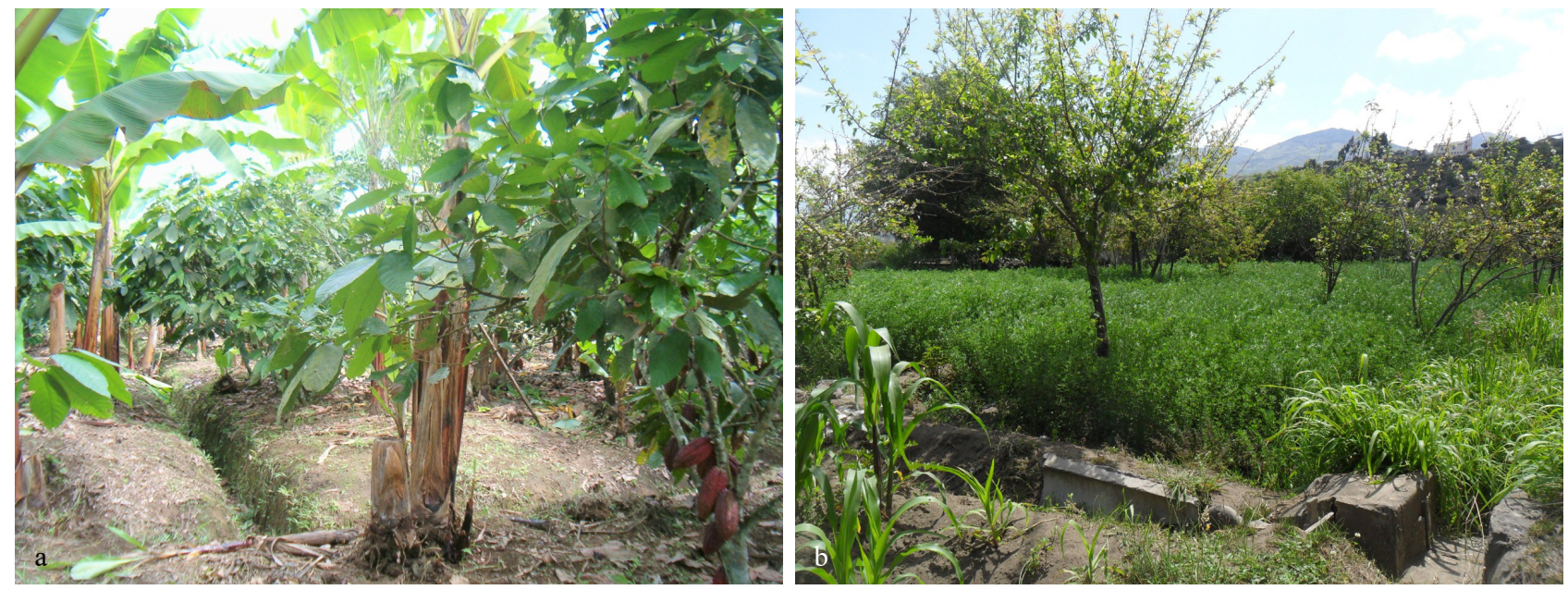

Figura 3. Asociación de cultivos con especies perennes-semiperennes: a. Ecuador-La Maná, b. Ecuador-Cevallos.

Figure 3. Crop association with perennial-semiperennial species: a. Ecuador-La Mana, b. Ecuador-Cevallos.

A pesar de que esta práctica puede ser más frecuente en zonas de clima tropical, es posible identificar su uso en valles interandinos (Figura 3). En Ecuador, los campesinos combinan cultivos de manzana (Malus sp.) y durazno (Prunus persica) con especies de ciclo corto o pastos como alfalfa (Medicago sativa) en arreglos conocidos como huertas frutícolas con el fin de maximizar el uso de la tierra y diversificar la oferta de productos (Tamayo, 2015).

(ii) Sistemas agroforestales

Los sistemas agroforestales consisten en la combinación de cultivos con árboles y/o arbustos implementados a fin de promover la diversificación de un agroecosistema, mejorar el microclima, controlar la erosión, dotar de fertilidad natural al suelo, capturar y almacenar carbono, mejorar y diversificar el ingreso familiar, entre otras bondades (Altieri, 2002; Jadán et al., 2012; Pocomucha et al., 2016). La diversidad de componentes puede variar en función del sistema productivo, como en el caso de sistemas multiestrato que combina cultivos, coberturas, frutos, leña y madera (Alegre Orihuela, 2015).

Las especies empleadas en sistemas agroforestales es amplia y la producción puede ser destinada tanto para la venta como para el consumo familiar (Jadán et al., 2012; Poveda et al., 2013). Además, los principales arreglos documentados en territorios campesinos consisten en combinaciones basados en el cacao y el café, en asocio con otras especies frutícolas y diversas especies de árboles maderables (Jadán et al., 2012; Pocomucha et al., 2016; Poveda et al., 2013; Salgado-Mora et al., 2018) (Figura 4).
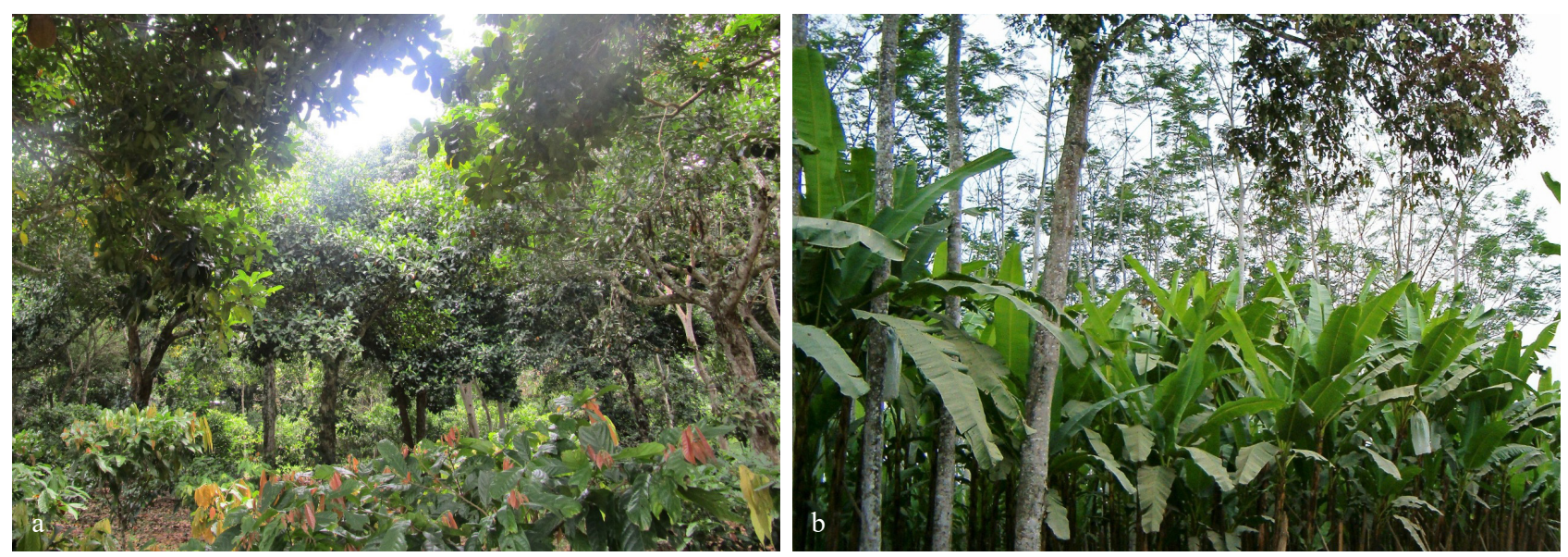

Figura 4. Asociación de cultivos en sistemas agroforestales: a. Perú-Yurimaguas, b. Ecuador-La Maná.

Figure 4. Crop association in agroforestry systems: a. Peru-Yurimaguas, b. Ecuador-La Mana. 
(iii) Sistemas silvopastoriles

Los sistemas silvopastoriles se fundamentan en la combinación de especies forrajeras, arbustos y árboles para la nutrición animal y usos complementarios (Murgueitio et al., 2011, citado en Reyes et al., 2017, p. 4). Al interior de esta categoría es posible identificar variantes como cercas vivas, árboles dispersos al interior de las parcelas, pasturas en plantaciones forestales, bancos de proteínas y sistemas intensivos con alta densidad de especies arbustivas y arbóreas (Reyes et al., 2017) (Figura 5). Además, su implementación puede ser aplicada a diversas orientaciones productivas como la crianza de ganado para carne, leche y doble propósito (Chará et al., 2018; Navas Panadero et al., 2020; Reyes et al., 2017; Rivera Herrera et al., 2012; Rivera et al., 2011, 2015; Urbano et al., 2006).
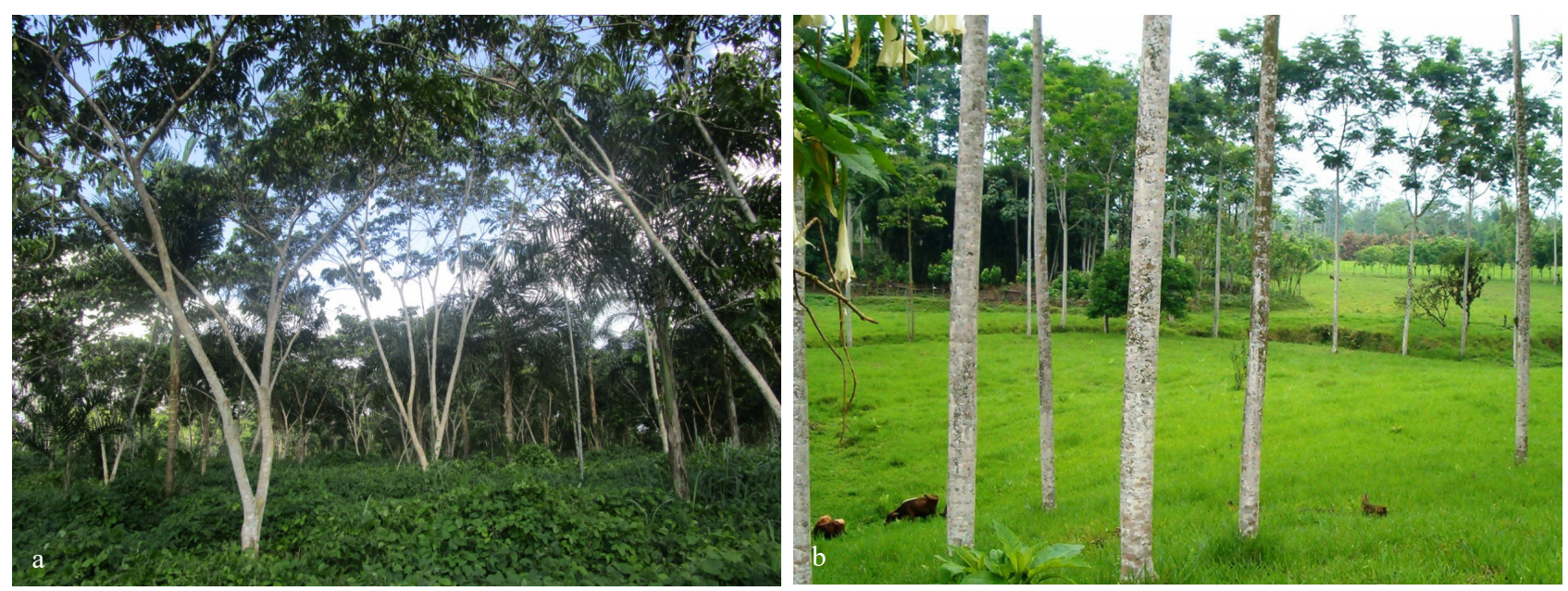

Figura 5. Sistemas silvopastoriles: a. Perú-Yurimaguas, b. Ecuador-La Maná.

Figure 5. Silvopastoral systems: a. Peru-Yurimaguas, b. Ecuador-La Mana.

Las principales especies utilizadas están relacionadas con el uso de gramíneas (para estratos herbáceos) en mezcla de leguminosas y asteráceas (componentes arbustivos y arbóreos) a fin de dotar a las crianzas de una alimentación balanceada, incrementar los rendimientos, mejorar las características del suelo y generar mayores ingresos agrícolas (Chamorro Viveros y Rey, 2017; Hernández Rodríguez y Ponce Ceballo, 2004; Rivera et al., 2011, 2015; Urbano et al., 2006).

\subsection{Importancia de la asociación de cultivos para una agricultura sustentable}

\subsubsection{Incremento de producción y mayor eficiencia de la tierra}

La obtención de mejor producción es un aspecto importante para el desarrollo de una agricultura sustentable. Al analizar investigaciones relacionadas con la asociación maíz-fréjol-calabaza (milpa) en México y Colombia, se evidencia atributos importantes en su siembra en comparación con su simplificación. Los principales resultados evidencian una mejor eficiencia en el uso de la tierra expresada en unidades equivalente de terreno (UET) o también denominada relación equivalente de terreno (RET), (Tabla 1); incluso, mientras más diverso es el arreglo, mejor resultado de este índice (Molina-Anzures et al., 2016).

A pesar de que el sistema en consorcio puede registrar mermas en el rendimiento de un determinado cultivo por la menor abundancia de una especie, en comparación con el sistema simplificado (Ebel et al., 2017); genera una mayor eficiencia en términos agronómicos al considerar el efecto individual de cada uno de los componentes y la producción generada como un conjunto, obteniéndose una respuesta global mayor que el monocultivo (Chargoy Zamora, 2004). También estudios realizados con mezcla de variedades de fréjol asociados e intercalados con maíz en Ecuador han reportado valores de índice equivalente de tierra (LER, por sus siglas en inglés), superiores a uno (Ochoa Lozano, 2018). 
Tabla 1. Eficiencia y rendimiento del sistema maíz, fréjol y calabaza en asociación y monocultivo.

Table 1. Efficiency and yield of the corn, bean and squash system in association and monoculture.

\begin{tabular}{|c|c|c|c|c|c|}
\hline \multirow{2}{*}{ Sistemas estudiados } & \multirow{2}{*}{ Aspectos analizados } & \multicolumn{2}{|c|}{ Resultados* } & \multirow{2}{*}{$\begin{array}{c}\text { Respuesta } \\
(+,-,=)\end{array}$} & \multirow{2}{*}{ Referencia } \\
\hline & & Aso. & Mon. & & \\
\hline $\begin{array}{l}\text { Asociación maíz, frijol, calabaza y } \\
\text { frutales vs. monocultivo. }\end{array}$ & RET & 3,40 & 0,69 & $(+)$ & $\begin{array}{l}\text { Molina-Anzures } \\
\quad(2016)\end{array}$ \\
\hline $\begin{array}{l}\text { Asociación maíz, frijol y calabaza vs. } \\
\text { monocultivo de frijol. }\end{array}$ & UET & 2,95 & 1,0 & $(+)$ & $\begin{array}{l}\text { Gómez-Betancur } \\
\text { et al. (2018) }\end{array}$ \\
\hline $\begin{array}{l}\text { Asociación maíz, frijol y calabaza vs. } \\
\text { monocultivo }\end{array}$ & RET & 1,6 & 1,0 & $(+)$ & \\
\hline $\begin{array}{l}\text { Asociación maíz, frijol y calabaza vs. } \\
\text { monocultivo de maíz }\end{array}$ & $\begin{array}{l}\text { Rendimiento maíz } \\
\quad\left(\mathrm{Mg} \mathrm{ha}^{-1}\right)\end{array}$ & 4,5 & 9,3 & $(-)$ & \\
\hline $\begin{array}{l}\text { Asociación maíz y frijol vs. mono- } \\
\text { cultivo de maíz }\end{array}$ & $\begin{array}{l}\text { Rendimiento maíz } \\
\qquad\left(\mathrm{Mg} \mathrm{ha}^{-1}\right)\end{array}$ & 7,9 & 9,3 & $(-)$ & Ebel et al. (2017) \\
\hline $\begin{array}{l}\text { Asociación maíz, frijol y calabaza vs. } \\
\text { monocultivo de frijol }\end{array}$ & $\begin{array}{l}\text { Rendimiento frijol } \\
\qquad\left(\mathrm{Mg} \mathrm{ha}^{-1}\right)\end{array}$ & 0,9 & 1,9 & $(-)$ & \\
\hline $\begin{array}{l}\text { Asociación maíz y frijol vs. mono- } \\
\text { cultivo frijol }\end{array}$ & $\begin{array}{l}\text { Rendimiento frijol } \\
\qquad\left(\mathrm{Mg} \mathrm{ha}^{-1}\right)\end{array}$ & 1,9 & 1,9 & $(=)$ & \\
\hline \multirow{3}{*}{$\begin{array}{l}\text { Asociación maíz, frijol y calabaza } \\
\text { ( } 45 \text { días posterior a siembra de maíz) } \\
\text { vs. monocultivo de frijol }\end{array}$} & Número de vainas & 11,1 & 14,1 & $(+)$ & \multirow{3}{*}{$\begin{array}{l}\text { Gómez-Betancur } \\
\text { et al. (2018) }\end{array}$} \\
\hline & $\begin{array}{l}\text { Peso de vainas } \\
\quad \text { (gramos) }\end{array}$ & 253,4 & 162,2 & $(+)$ & \\
\hline & $\begin{array}{l}\text { Rendimiento frijol } \\
\qquad\left(\mathrm{kg} \mathrm{ha}^{-1}\right)\end{array}$ & 1801 & 1050 & $(+)$ & \\
\hline
\end{tabular}

*Aso.: Asociado; Mon.: Monocultivo

La mejor eficiencia registrada en policultivos no se limita a sistemas cultivados tradicionalmente como la milpa. También investigaciones realizadas con especies hortícolas en Brasil reportan beneficios sustanciales. Las mejoras obtenidas están relacionadas con incremento en el peso, diámetro y materia seca del producto, mejor calidad química del alimento e incremento de rendimientos (Tabla 2 y Tabla 3). Sin embargo, a pesar de estas bondades, se puede registrar una reducción en la cantidad cosechada por rubro por la menor abundancia de individuos por especie en una asociación hortícola (Salgado et al., 2006). A pesar de existir casos en los que se registra mermas en el rendimiento, la siembra de hortalizas en consorcio registra mejores valores de UET, incluso cercanos a dos (Figura 6).

Tabla 2. Características físico-químicas de sistemas hortícolas en asociación y monocultivo.

Table 2. Physico-chemical characteristics of horticultural systems in association and monoculture.

\begin{tabular}{|c|c|c|c|c|c|}
\hline \multirow{2}{*}{ Sistemas estudiados } & \multirow{2}{*}{ Aspectos analizados } & \multicolumn{2}{|c|}{ Resultados } & \multirow{2}{*}{$\begin{array}{c}\text { Respuesta } \\
(+,-,=)\end{array}$} & \multirow{2}{*}{ Referencia } \\
\hline & & Aso. & Mon. & & \\
\hline \multirow{4}{*}{$\begin{array}{l}\text { Asociación tomate con maíz con } \\
\text { orientación de hileras norte a sur } \\
\text { vs. monocultivo de tomate }\end{array}$} & $\begin{array}{l}\text { Número de frutos } \\
\text { por planta }\end{array}$ & 17,62 & 12,55 & $(+)$ & \multirow{4}{*}{ Pino (2001) } \\
\hline & Acidez (\%) & 0,31 & 0,41 & $(+)$ & \\
\hline & Brix $(\%)$ & 4,87 & 3,72 & $(+)$ & \\
\hline & Materia seca (\%) & 5,51 & 4,91 & $(+)$ & \\
\hline $\begin{array}{l}\text { Asociación lechuga con rábano } \\
\text { vs. monocultivo de rábano }\end{array}$ & $\begin{array}{c}\text { Materia seca de } \\
\text { raíces de rábano }\left(\mathrm{g} \mathrm{m}^{2-1}\right)\end{array}$ & 67,87 & 54,89 & $(+)$ & $\begin{array}{l}\text { Cecílio Filho y May } \\
\text { (2002) }\end{array}$ \\
\hline \multirow{2}{*}{$\begin{array}{l}\text { Asociación lechuga crespa con } \\
\text { zanahoria vs. monocultivo de le- } \\
\text { chuga ( } 2 \text { año de cultivo). }\end{array}$} & Peso (g planta-1) & 423,2 & 342,7 & $(+)$ & \multirow{4}{*}{ Salgado et al. (2006) } \\
\hline & Diámetro (cm) & 43,7 & 38,8 & $(+)$ & \\
\hline \multirow{2}{*}{$\begin{array}{l}\text { Asociación zanahoria con lechu- } \\
\text { ga lisa vs. monocultivo de zana- } \\
\text { horia ( } 1 \text { año de cultivo). }\end{array}$} & Peso (g planta ${ }^{-1}$ ) & 75,3 & 44,5 & $(+)$ & \\
\hline & Diámetro $(\mathrm{cm})$ & 2,94 & 2,40 & $(+)$ & \\
\hline
\end{tabular}


Tabla 3. Rendimiento de sistemas hortícolas en asociación y monocultivo

Table 3. Yield of horticultural systems in association and monoculure

\begin{tabular}{|c|c|c|c|c|c|}
\hline \multirow{2}{*}{ Sistemas estudiados } & \multirow{2}{*}{ Aspectos analizados } & \multicolumn{2}{|c|}{ Resultados } & \multirow{2}{*}{$\begin{array}{c}\text { Respuesta } \\
(+,-,=)\end{array}$} & \multirow{2}{*}{ Referencia } \\
\hline & & Aso. & Mon. & & \\
\hline \multirow{2}{*}{$\begin{array}{l}\text { Asociación tomate con maíz con orienta- } \\
\text { ción de hileras norte a sur vs. monocultivo } \\
\text { de tomate }\end{array}$} & Rendimiento tomate $\left(\mathrm{t} \mathrm{ha}^{-1}\right)$ & 23 & 18,15 & $(+)$ & \multirow{2}{*}{ Pino (2001) } \\
\hline & Número de frutos por planta & 17,62 & 12,55 & $(+)$ & \\
\hline $\begin{array}{l}\text { Asociación lechuga lisa con zanahorita vs } \\
\text { monocultivo de lechuga (plantío 1) }\end{array}$ & Rendimiento ( $\left.\mathrm{t} \mathrm{ha}^{-1}\right)$ & 6,46 & 13,13 & $(-)$ & $\begin{array}{l}\text { Oliveira et al. } \\
\text { (2004) }\end{array}$ \\
\hline \multirow{2}{*}{$\begin{array}{l}\text { Asociación pimiento con lechuga vs. mono- } \\
\text { cultivo. }\end{array}$} & Producción pimiento $\left(\mathrm{kg} \mathrm{ha}^{-1}\right)$ & 37.378 & 35.698 & $(+)$ & \multirow{2}{*}{$\begin{array}{l}\text { Rezende et al. } \\
\text { (2005) }\end{array}$} \\
\hline & Producción lechuga $\left(\mathrm{kg} \mathrm{ha}^{-1}\right)$ & 46.344 & 33.077 & $(+)$ & \\
\hline $\begin{array}{l}\text { Asociación lechuga crespa con zanahoria } \\
\text { vs. monocultivo de lechuga (primer año } \\
\text { de cultivo). }\end{array}$ & Productividad (Mg ha'-1) & 26,7 & 54,9 & $(-)$ & \multirow{2}{*}{$\begin{array}{l}\text { Salgado et al. } \\
\quad \text { (2006) }\end{array}$} \\
\hline $\begin{array}{l}\text { Asociación zanahoria con lechuga lisa vs. } \\
\text { monocultivo de zanahoria (primer año de } \\
\text { cultivo). }\end{array}$ & Productividad $\left(\mathrm{Mg} \mathrm{ha}^{-1}\right)$ & 44,5 & 36,8 & $(+)$ & \\
\hline $\begin{array}{l}\text { Asociación lechuga crespa con rúcula vs. } \\
\text { monocultivo de lechuga }\end{array}$ & Producción (kg ha-1) & $16.275,60$ & $18.394,64$ & $(-)$ & $\begin{array}{l}\text { Barros Júnior } \\
\text { et al. (2008) }\end{array}$ \\
\hline $\begin{array}{l}\text { Asociación lechuga crespa con pepino } \\
\text { bajo cubierta vs. monocultivo de lechuga }\end{array}$ & $\begin{array}{l}\text { Productividad } \\
\left(\mathrm{kg} 614,4 \mathrm{~m}^{2-1}\right)\end{array}$ & 822,53 & 890,78 & $(-)$ & $\begin{array}{l}\text { Silva et al. } \\
\quad(2008)\end{array}$ \\
\hline $\begin{array}{l}\text { Asociación lechuga con pimiento vs. mo- } \\
\text { nocultivo de lechuga }\end{array}$ & Producción $\left(\mathrm{kg} \mathrm{ha}^{-1}\right)$ & 46.344 & 33.077 & $(+)$ & \multirow{2}{*}{$\begin{array}{l}\text { Rezende et al. } \\
\text { (2009) }\end{array}$} \\
\hline $\begin{array}{l}\text { Asociación rabanito con pimiento vs. mo- } \\
\text { nocultivo de rabanito }\end{array}$ & Producción (kg ha-1) & 17.908 & 16.721 & $(+)$ & \\
\hline
\end{tabular}

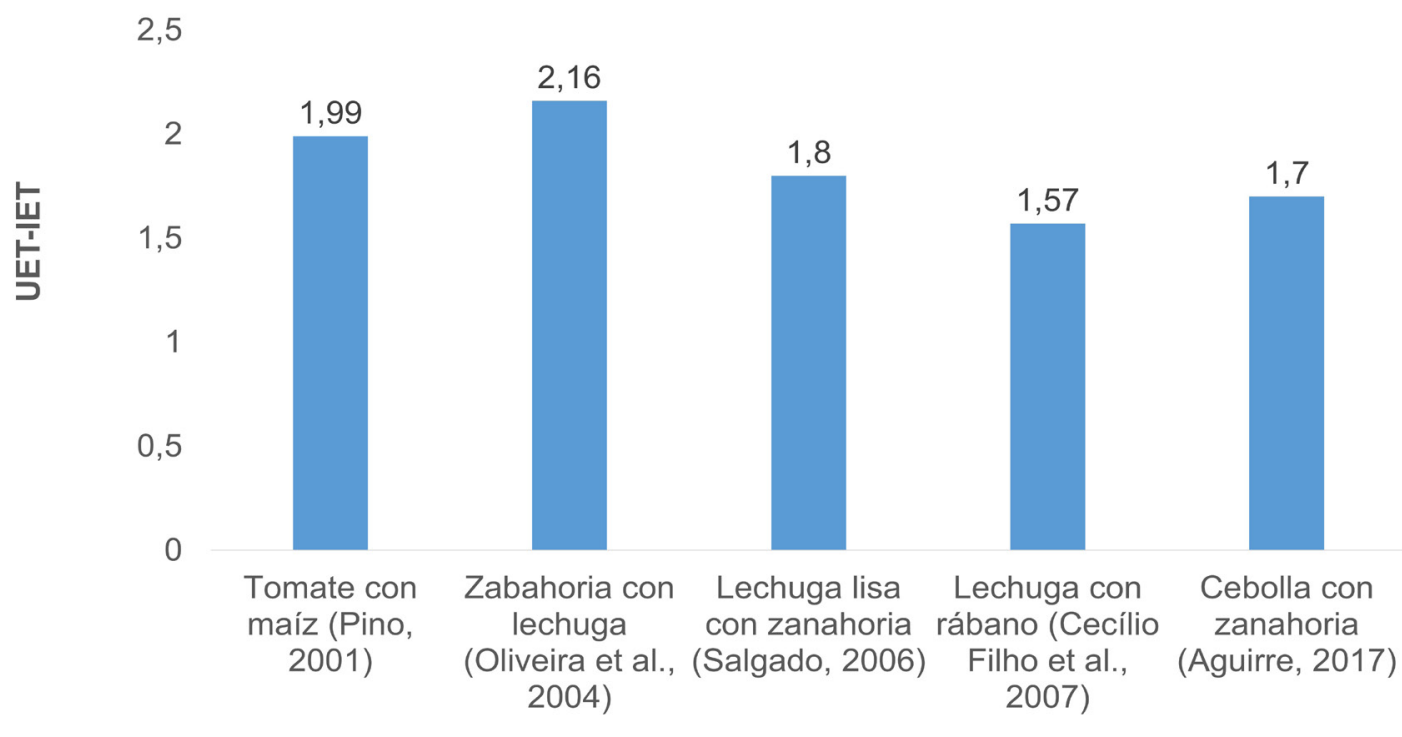

Tipo de asociación

Figura 6. Eficiencia del uso de la tierra en diferentes sistemas hortícolas. A partir de Pino (2001), Oliveira et al. (2004), Salgado (2006), Cecílio Filho et al. (2007), Aguirre (2017).

Figure 6. Efficiency of land use in different horticultural systems. Source: Pino (2001), Oliveira et al. (2004), Salgado (2006), Cecilio Filho et al. (2007), Aguirre (2017).

Adicionalmente, las bondades de la siembra asociada se pueden identificar en cultivos perennes puros o intercalados con cultivos de ciclo corto (Tabla 4). También, la asociación de varias especies de musáceas destinadas a la exportación y al mercado local en Ecuador ha registrado mayores rendimientos y el doble de la eficiencia global que el monocultivo. 
Tabla 4. Eficiencia y rendimiento de sistemas perennes en asociación y monocultivo.

Table 4. Efficiency and yield of perennial systems in association and monoculture.

\begin{tabular}{|c|c|c|c|c|c|}
\hline \multirow[b]{2}{*}{ Sistemas estudiados } & \multirow[b]{2}{*}{ Aspectos analizados } & \multicolumn{2}{|c|}{ Resultados } & \multirow{2}{*}{$\begin{array}{l}\text { Respuesta } \\
(+,-,=)\end{array}$} & \multirow[b]{2}{*}{ Referencia } \\
\hline & & Aso. & Mon. & & \\
\hline $\begin{array}{l}\text { Rambutan con intercalamiento de maíz, frijol y } \\
\text { calabaza vs. monocultivo de rambutan }\end{array}$ & $\begin{array}{l}\text { Rendimiento } \\
\left(\mathrm{t} \mathrm{ha}^{-1}\right)\end{array}$ & 2,7 & 2,6 & $(=)$ & $\begin{array}{l}\text { Osorio-Espinoza } \\
\text { et al. }(2017)\end{array}$ \\
\hline \multirow{3}{*}{$\begin{array}{l}\text { Orito asociado con otras especies de Musas vs. } \\
\text { monocultivo de orito (Musa Acuminata AA) }\end{array}$} & $\begin{array}{l}\text { Rendimiento } \\
\left(\mathrm{kg} \mathrm{ha}^{-1} \mathrm{año}^{-1}\right)\end{array}$ & 19.777 & 13.474 & $(+)$ & \multirow{3}{*}{ Vera (2017) } \\
\hline & $\begin{array}{l}\text { Rendimiento } \\
\left(\text { cajas ha }{ }^{-1} \text { año }^{-1}\right)\end{array}$ & 719 & 490 & $(+)$ & \\
\hline & RET & 2,0 & 1 & $(+)$ & \\
\hline
\end{tabular}

Tabla 5. Producción de leche en sistemas silvopastoriles y monocultivo de pastos.

Table 5. Milk production in sylvopastoral systems and pastures in monoculture.

\begin{tabular}{|c|c|c|c|c|c|}
\hline \multirow{2}{*}{ Sistemas estudiados } & \multirow{2}{*}{$\begin{array}{l}\text { Aspecto analizado } \\
\text { (Producción) }\end{array}$} & \multicolumn{2}{|c|}{ Resultados } & \multirow{2}{*}{$\begin{array}{c}\text { Respuesta } \\
(+,-,=)\end{array}$} & \multirow{2}{*}{ Referencia } \\
\hline & & Aso. & Mon. & & \\
\hline \multirow{2}{*}{$\begin{array}{l}\text { Incorporación de leucaena y matarratón en } \\
\text { pasturas vs. cultivo de gramíneas sin árboles }\end{array}$} & 1 vaca $^{-1}$ día $^{-1}$ & 8,96 & 8,21 & $(=)$ & \multirow{2}{*}{$\begin{array}{l}\text { Urbano et al. } \\
\qquad(2006)\end{array}$} \\
\hline & 1 ha $^{-1}$ año $^{-1}$ & 13.343 & 5.244 & $\begin{array}{l}\text { No se } \\
\text { especifica }\end{array}$ & \\
\hline $\begin{array}{l}\text { Incorporación de botón de oro y árboles ma- } \\
\text { derables en pasturas vs. monocultivo de pastos }\end{array}$ & $\mathrm{kg} \mathrm{ha}^{-1} \mathrm{dí}^{-1}$ & 15,03 & 9,51 & $(+)$ & $\begin{array}{l}\text { Rivera et al. } \\
\quad(2011)\end{array}$ \\
\hline $\begin{array}{l}\text { Incorporación de leucaena y árboles dispersos } \\
\text { en pasturas vs. sistema convencional sin árboles } \\
\text { ni arbustos }\end{array}$ & $\begin{array}{l}\mathrm{kg} \text { vaca }^{-1} \\
\text { día }^{-1}\end{array}$ & 4,13 & 3,54 & $(+)$ & $\begin{array}{l}\text { Rivera Herrera } \\
\text { et al. }(2012)\end{array}$ \\
\hline \multirow{2}{*}{$\begin{array}{l}\text { Incorporación de botón de oro y árboles de } \\
\text { sombra en pasturas de braquiarias vs. mono- } \\
\text { cultivo pastos }\end{array}$} & 1 vaca $^{-1}$ día $^{-1}$ & 4,92 & 4,59 & $(+)$ & \multirow{2}{*}{$\begin{array}{l}\text { Rivera et al. } \\
\quad(2015)\end{array}$} \\
\hline & 1 ha $^{-1}$ día $^{-1}$ & 15,4 & 9,70 & $(+)$ & \\
\hline $\begin{array}{l}\text { Incorporación de aliso en pradera de kikuyo } \\
\text { vs. monocultivo kikuyo }\end{array}$ & 1 vaca $^{-1}$ día $^{-1}$ & 14,38 & 12,76 & $(+)$ & $\begin{array}{c}\text { Chamorro Viveros } \\
\text { y Rey (2017) }\end{array}$ \\
\hline
\end{tabular}

El mejoramiento de la producción al incorporar biodiversidad también se puede identificar en la crianza de ganado bovino. Investigaciones realizadas en Colombia, México y Argentina en fincas con diversas orientaciones productivas (leche, engorde y doble propósito) evidencian importantes efectos tras implementar sistemas silvopastoriles. Los principales resultados registrados en el transcurso de casi una década de estudio están relacionados con la ampliación de la superficie aprovechable de los predios, incremento de hasta siete veces la cantidad de forraje por hectárea, aumento en la carga animal; y, en consecuencia, el ascenso de la productividad de leche por hectárea (entre el 60 y el $314 \%$ ) y de carne en alrededor del 900 \% al finalizar el noveno año de evaluación (Chará et al., 2018; Reyes et al., 2017).

Las diferencias con los sistemas tradicionales que no incorporan especies arbóreas también se originan por el aumento en la producción a nivel de especie animal. Los rendimientos registrados en sistemas asociados reflejan mejoras entre el 7 y el $16 \%$ en la producción de leche por vaca al día (Tabla 5). Adicionalmente, la calidad del producto generado puede superar a la lógica de crianza basada en pastoreo en unicultivo (Tabla 6).

Las mejoras obtenidas con esta innovación están asociadas a la interacción entre componentes del sistema productivo originados con la incorporación de especies arbóreas y arbustivas (Figura 7). Al respecto, son varias las investigaciones que demuestran su efecto positivo por el mayor crecimiento de pasto registrado debajo de las copas de los árboles (Navas Panadero et al., 2020), incremento en el rendimiento de forraje verde (Oliva et al., 2018), mejor calidad nutricional del pasto (Romero Delgado et al., 2020), mayor digestibilidad (Obispo et al., 2008), reducción del estrés calórico en los animales por presencia de sombra (Chará et al., 2018; Navas Panadero, 2010), regulación de parásitos que afectan a los rumiantes (Murgueitio y Giraldo, 2009), mayor eficiencia de infiltración del agua y humedad en las parcelas (Chamorro Viveros y Rey, 2017; Ríos et al., 2006) e incremento de la fertilidad y actividad biológica del suelo (Chamorro Viveros y Rey, 2017; Escobar et al., 2020; Hernández Chávez et al., 2008; Navas Panadero et al., 2020; Sánchez et al., 2003). 
Tabla 6. Calidad de la leche en sistemas silvopastoriles y monocultivos de pastos.

Table 6. Milk quality in sylvopastoral systems and pastures in monoculture.

\begin{tabular}{|c|c|c|c|c|c|}
\hline \multirow{2}{*}{ Sistemas estudiados } & \multirow{2}{*}{ Aspectos analizados } & \multicolumn{2}{|c|}{ Resultados } & \multirow{2}{*}{$\begin{array}{c}\text { Respuesta } \\
(+,-,=)\end{array}$} & \multirow{2}{*}{ Referencia } \\
\hline & & Aso. & Mon. & & \\
\hline \multirow{2}{*}{$\begin{array}{l}\text { Incorporación de leucaena en pasto estrella vs. } \\
\text { monocultivo de pasto estrella }\end{array}$} & Grasa en leche $(\%)$ & 3,75 & 3,50 & $(+)$ & \multirow{2}{*}{$\begin{array}{c}\text { Hernández } \\
\text { Rodríguez y Ponce } \\
\text { Ceballo (2004) } \\
\end{array}$} \\
\hline & Sólidos totales (\%) & 12,2 & 11,7 & $(+)$ & \\
\hline \multirow{2}{*}{$\begin{array}{l}\text { Incorporación de leucaena y árboles dispersos } \\
\text { en pasturas vs. sistema convencional sin árbo- } \\
\text { les ni arbustos }\end{array}$} & Grasa (\%) & 5,45 & 4,3 & $(+)$ & \multirow{2}{*}{$\begin{array}{l}\text { Rivera Herrera } \\
\text { et al. }(2012)\end{array}$} \\
\hline & Sólidos totales (\%) & 14,59 & 13,24 & $(+)$ & \\
\hline \multirow{3}{*}{$\begin{array}{l}\text { Incorporación de botón de oro y árboles de } \\
\text { sombra en pasturas de braquiarias vs. sistema } \\
\text { convencional }\end{array}$} & Grasa en leche (\%) & 3,48 & 3,54 & $(=)$ & \multirow{3}{*}{ Rivera et al. (2015) } \\
\hline & Sólidos totales (\%) & 12,2 & 12,2 & $(=)$ & \\
\hline & $\begin{array}{l}\text { Sólidos totales kg } \\
\text { vaca }^{-1} \text { día }^{-1}\end{array}$ & 0,62 & 0,55 & $(+)$ & \\
\hline
\end{tabular}

(1)

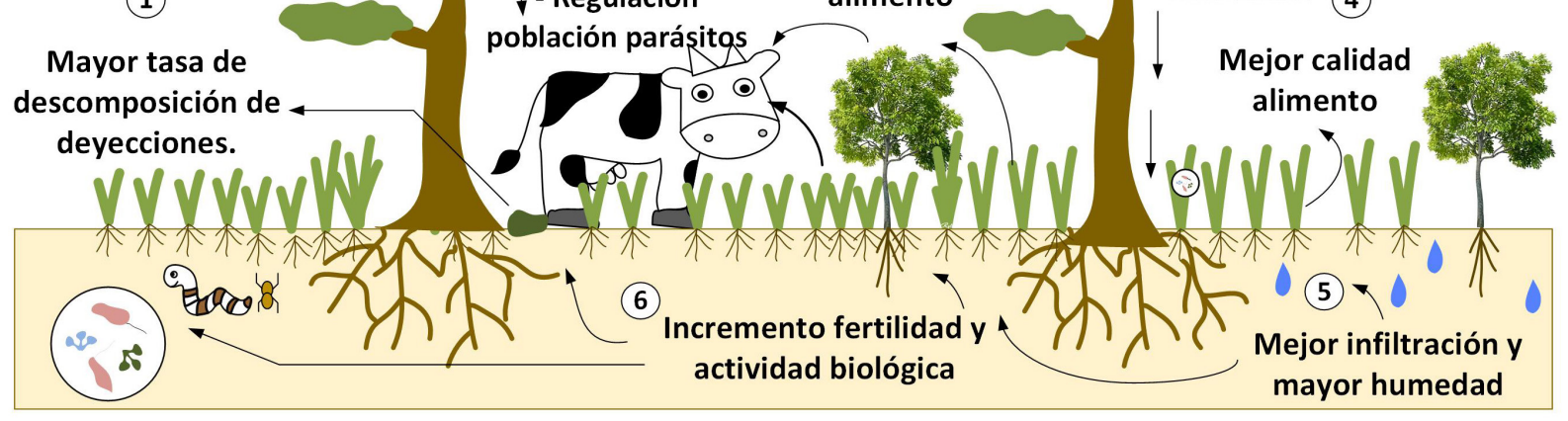

Figura 7. Beneficios de los sistemas silvopastoriles para la ganadería. Elaborador a partir de (1) Soca et al. (2002), Soca et al. (2006); (2) Murgueitio y Giraldo (2009), Navas Panadero (2010), Chará et al. (2018); (3) Oliva et al. (2018); (4) Obispo et al. (2008), Romero Delgado et al. (2020); (5) Ríos et al. (2006), Chamorro Viveros y Rey (2017); (6) Sánchez et al. (2003), Hernández Chávez et al. (2008), Chamorro Viveros y Rey (2017), Escobar et al. (2020), Navas Panadero et al. (2020).

Figure 7. Benefits of silvopastoral systems for livestock. Sources: Soca et al. (2002), Soca et al. (2006); (2) Murgueitio y Giraldo (2009), Navas Panadero (2010), Chará et al. (2018); (3) Oliva et al. (2018); (4) Obispo et al. (2008), Romero Delgado et al. (2020); (5) Ríos et al. (2006), Chamorro Viveros y Rey (2017); (6) Sánchez et al. (2003), Hernández Chávez et al. (2008), Chamorro Viveros y Rey (2017), Escobar et al. (2020), Navas Panadero et al. (2020).

A pesar de las respuestas positivas identificadas, también existen investigaciones cuyos resultados no presentan diferencias significativas con los sistemas convencionales en relación al contenido nutricional del pasto (Oliva et al., 2018; Rivera et al., 2011), nivel de producción láctea (Urbano et al., 2006) y calidad de la leche (Chamorro Viveros y Rey, 2017; Rivera et al., 2015); incluso, pueden identificarse respuestas desfavorables para el consorcio en la producción de forraje por influencia de altos y medianos niveles de sombra (Obispo et al., 2008) y disminución en la tasa de crecimiento de vegetación que demanda altos niveles de luminosidad (Romero Delgado et al., 2020). Sin embargo, si los resultados obtenidos se proyectan con indicadores más amplios a nivel de superficie y año (Rivera et al., 2015; Urbano et al., 2006); y sobre todo si se visualizan de manera integral, el balance cambia notablemente a favor de los sistemas silvopastoriles. Además, sus atributos positivos los consolidan como una opción adecuada para la producción y consumo responsable de alimentos de origen bovino (Chará et al., 2017). 
Tabla 7. Beneficio económico en sistemas asociados y monocultivos.

Table 7. Economic profit in crop association and monocultures.

\begin{tabular}{|c|c|c|c|c|c|}
\hline \multirow{2}{*}{ Sistemas estudiados } & \multirow{2}{*}{$\begin{array}{c}\text { Aspectos } \\
\text { Analizados* }\end{array}$} & \multicolumn{2}{|c|}{ Resultados } & \multirow{2}{*}{$\begin{array}{c}\text { Respuesta } \\
(+,-,=)\end{array}$} & \multirow{2}{*}{ Referencia } \\
\hline & & Aso. & Mon. & & \\
\hline $\begin{array}{l}\text { Asociación tomate con maíz (como som- } \\
\text { bra) con orientación de hileras norte a sur } \\
\text { vs. monocultivo de tomate }\end{array}$ & $\begin{array}{l}\text { Beneficio costo b/c } \\
\text { (Pesos cubanos) }\end{array}$ & 2,53 & 1,19 & $(+)$ & Pino (2001) \\
\hline $\begin{array}{l}\text { Asociación lechuga con rábano vs. mono- } \\
\text { cultivo de lechuga }\end{array}$ & $\begin{array}{l}\text { Ingreso } \\
\left(\mathrm{R} \$ \mathrm{ha}^{-1}\right)\end{array}$ & $26.540,61$ & $18.036,29$ & $(+)$ & $\begin{array}{l}\text { Cecílio Filho y } \\
\text { May (2002) }\end{array}$ \\
\hline \multirow{3}{*}{$\begin{array}{l}\text { Asociación pimiento con lechuga vs. mo- } \\
\text { nocultivo de pimiento }\end{array}$} & $\begin{array}{l}\text { Costos Totales } \\
\left(\mathrm{R} \$ \mathrm{ha}^{-1}\right)\end{array}$ & $6.783,61$ & $5.042,24$ & $(-)$ & \multirow{3}{*}{$\begin{array}{l}\text { Rezende } \text { et al. } \\
\qquad(2005)\end{array}$} \\
\hline & $\begin{array}{l}\text { Ingreso líquido } \\
\quad\left(\mathrm{R} \$ \mathrm{ha}^{-1}\right)\end{array}$ & $48.847,98$ & $19.060,34$ & $(+)$ & \\
\hline & Tasa de retorno & 8,20 & 4,78 & $(+)$ & \\
\hline \multirow{2}{*}{$\begin{array}{l}\text { Asociación lechuga crespa con rúcula vs. } \\
\text { monocultivo de lechuga }\end{array}$} & $\begin{array}{l}\text { Costo Total } \\
\left(\mathrm{R} \$ \mathrm{ha}^{-1}\right)\end{array}$ & 7195,46 & 5446,42 & $(-)$ & \multirow{2}{*}{$\begin{array}{l}\text { Barros Júnior et } \\
\quad \text { al. (2008) }\end{array}$} \\
\hline & $\begin{array}{l}\text { Utilidad } \\
\left(\mathrm{R} \$ \mathrm{ha}^{-1}\right)\end{array}$ & $29.270,73$ & $12.396,38$ & $(+)$ & \\
\hline \multirow{2}{*}{$\begin{array}{l}\text { Asociación lechuga crespa con pepino } \\
\text { (bajo cubierta) vs. monocultivo de lechuga }\end{array}$} & $\begin{array}{l}\text { Costos Totales } \\
\left(\mathrm{R} \$ 614.4 \mathrm{~m}^{2-1}\right)\end{array}$ & 295,06 & 696,37 & $(+)$ & \multirow{2}{*}{ Silva et al. (2008) } \\
\hline & $\begin{array}{l}\text { Ganancias } \\
\quad(\mathrm{R} \$)\end{array}$ & 157,33 & $-206,44$ & $(+)$ & \\
\hline $\begin{array}{l}\text { Asociación lechuga con pimiento vs. mo- } \\
\text { nocultivo de lechuga }\end{array}$ & $\begin{array}{l}\text { Ingresos netos } \\
\qquad\left(\mathrm{R} \$ \mathrm{ha}^{-1}\right)\end{array}$ & $44.138,34$ & $29.502,91$ & $(+)$ & \multirow{2}{*}{$\begin{array}{l}\text { Rezende et al. } \\
\qquad(2009)\end{array}$} \\
\hline $\begin{array}{l}\text { Asociación rabanito con pimiento vs. mo- } \\
\text { nocultivo de rabanito }\end{array}$ & $\begin{array}{l}\text { Ingresos netos } \\
\qquad\left(\mathrm{R} \$ \mathrm{ha}^{-1}\right)\end{array}$ & $21.127,26$ & $18.548,76$ & $(+)$ & \\
\hline $\begin{array}{l}\text { Asociación maíz con poroto Tape y bonia- } \\
\text { to vs. monocultivo de maíz }\end{array}$ & $\begin{array}{l}\text { Ingresos brutos } \\
\quad\left(\text { usd ha }{ }^{-1}\right)\end{array}$ & 11.117 & 9.947 & $(+)$ & Aguirre (2017) \\
\hline
\end{tabular}

* $\mathrm{R} \$=$ Reales brasileños

\subsubsection{Mejoramiento de ingresos y mayor rentabilidad}

Las ventajas de los cultivos múltiples también se evidencian al momento de evaluar el nivel de rédito económico alcanzado. Según el tipo de arreglo implementado se puede identificar incrementos en el ingreso entre el $10 \mathrm{y}$ 150 \% (Tabla 7). En efecto, Gutiérrez-Martínez et al. (2007) al evaluar económicamente el sistema maíz-fréjol-calabaza en Chiapas-México, obtuvieron beneficios netos que superaron ampliamente al monocultivo de maíz (incluso en más del $100 \%$ ). También Aguirre (2017) registró mayores ingresos, más del $10 \%$, cuando este cereal estuvo en asocio con poroto caupí (Vigna unguiculata) y boniato (Ipomea batatas) 0.8 en Uruguay.

Los sistemas hortícolas implementados en la lógica del consorcio también registran mayores utilidades y ganancias. Estudios realizados en Brasil reportan ingresos significativamente mayores, entre el 10 y el 100 $\%$, cuando diferentes especies de hortalizas se cultivan de forma asociada (Barros Júnior et al., 2008; Cecílio Filho y May, 2002; Rezende et al., 2005, 2009; Silva et al., 2008).

Adicionalmente, la crianza de bovinos para leche, engorde o doble propósito en sistemas silvopastoriles dan cuenta de un progresivo aumento del retorno económico hasta en más del $100 \%$ por una mayor disponibilidad de forraje, carga animal e incremento de producción láctea (Chará et al., 2018; Reyes et al., 2017; Rivera Herrera et al., 2012). A pesar que sus limitaciones estarían relacionadas con el costo de implementación y la obtención de un flujo negativo de ingresos en los primeros años de explotación (Mahecha, 2003; Reyes et al., 2017); el nivel de ganancia obtenido, una vez recuperada la inversión, da cuenta de la potencialidad económica de este tipo de arreglo (Chará et al., 2018).

Finalmente es necesario indicar que la mayor ganancia generada en sistemas múltiples se debe a la cuantificación y valorización global de la producción obtenida (Chargoy Zamora, 2004). En algunos casos el costo total de establecimiento se incrementa por una mayor inversión en insumos como plántulas y costo de mano de obra (Barros Júnior et al., 2008; Rezende et al., 2005); sin embargo, las ganancias pueden superar ampliamente al monocultivo con cifras que pueden ser más del doble (Tabla 7). 


\subsubsection{Mitigación del cambio climático y almacenamiento de carbono}

La modificación del ambiente provocada por el cambio climático podría poner en riesgo la posibilidad de generar alimentos de una manera estable y suficiente (Vargas, 2011). Este fenómeno es generado por el incremento de gases de efecto invernadero (GEI) en la atmósfera, principalmente dióxido de carbono $\left(\mathrm{CO}_{2}\right)$, metano $\left(\mathrm{CH}_{4}\right)$ y óxido nitroso $\left(\mathrm{N}_{2} \mathrm{O}\right)$ (Grupo Intergubernamental de Expertos sobre el Cambio Climático [IPCC], 2013). Frente a esto, la implementación de cultivos asociados constituye una estrategia eficaz a fin de almacenar carbono y disminuir la emisión de GEI asociados a la actividad agropecuaria.

Las tasas de secuestro de $\mathrm{CO}_{2}, \mathrm{~N}_{2} \mathrm{O}$ y $\mathrm{CH}_{4}$ están relacionadas con la biodiversidad existente en los predios agropecuarios. Los arreglos de tipo agroforestal han sido los principales sistemas investigados en este aspecto, principalmente en zonas tropicales de Perú, Colombia Ecuador, México, Nicaragua, Costa Rica y Bolivia. Los resultados hallados demuestran mayor capacidad de almacenamiento de carbono (Alegre, 2017; Canal Daza y Andrade, 2019; Jadán et al., 2012; Palm et al., 2002). También, la incorporación de árboles en pasturas para crianza de bovinos en sistemas silvopastoriles registra una disminución en la emisión de $\mathrm{CO}_{2}$ entre el 11 y el $40 \%$ (Reyes et al., 2017). Adicionalmente, los predios con mayor diversidad presentan tasas reducidas de emisiones de $\mathrm{N}_{2} \mathrm{O}$ y bajo consumo de $\mathrm{CH}_{4}$; a diferencia de sistemas anuales basados en una sola especie donde se puede registrar emisiones de $\mathrm{CH}_{4}$ (Palm et al., 2002).

El almacenamiento de carbono en un sistema agrícola se cuantifica en función de sus componentes, principalmente suelo, biomasa aérea, raíces y manto de hojas secas. En la mayoría de estudios la mayor cantidad se registra en el suelo con rangos entre el 40 y el $90 \%$. En segundo lugar, se ubica en la biomasa aérea (6 al $36 \%$ ), seguido de hojarasca, raíces, componente herbáceo y troncos caídos con porcentajes inferiores al 12 $\%$ en conjunto (Jadán et al., 2012; Masuhara et al., 2015; Poveda et al., 2013). Sin embargo, también existen evidencias donde el mayor acopio se sitúa en la biomasa vegetal por influencia de las especies arbóreas (Alegre, 2017; Corral et al., 2006; Pocomucha et al., 2016), principalmente por su acumulación en la madera (47-50 \%) y en hojas (alrededor del $39 \%$ ) (Salgado-Mora et al., 2018), (Figura 8).

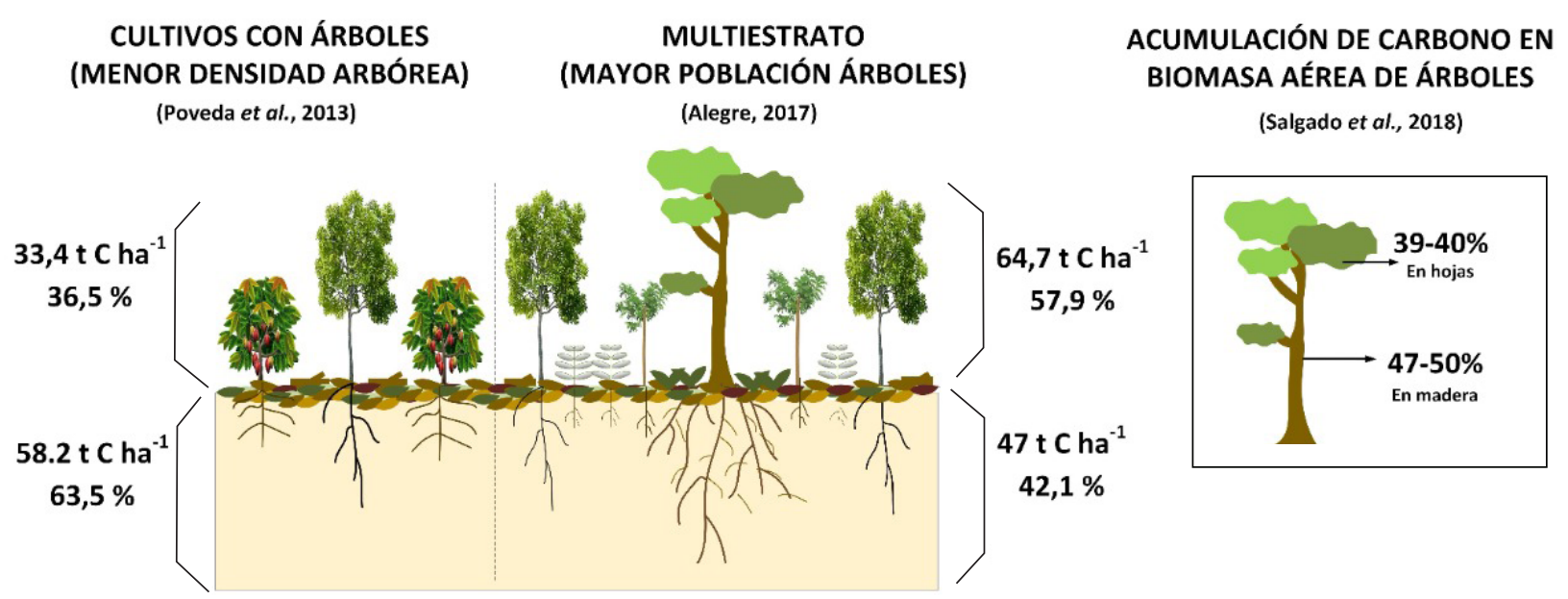

Figura 8. Almacenamiento de carbono en sistemas agroforestales. Elaboración a partir de Poveda et al. (2013); Alegre (2017); Salgado-Mora et al. (2018).

Figure 8. Carbon storage in agroforestry systems. Sources: Poveda et al. (2013); Alegre (2017); Salgado-Mora et al. (2018).

Las bondades de los policultivos se hacen mucho más evidentes cuando se compara el acopio de carbono en la biomasa de las especies vegetales, donde los sistemas agroforestales superan ampliamente a los monocultivos (Tabla 8). Sin embargo, los contrastes en relación con la cantidad fijada en el suelo se acortan, incluso con casos que no presentan diferencias significativas.

Los contrastes en el nivel de almacenamiento de carbono también se pueden identificar entre sistemas agroforestales. Las diferencias en un mismo territorio o entorno agroecológico se originan por el arreglo implementado, temporalidad de componentes, grado de diversidad y tipo de especies arbóreas utilizadas (Alegre, 2017; Andrade et al., 2014; Canal Daza y Andrade, 2019; Masuhara et al., 2015; Poveda et al., 2013; Vega Orozco et al., 2014); en tanto que, entre lugares geográficos, considerando diseños similares, se dan por factores climáticos y edáficos (Corral et al., 2006). 
Tabla 8. Almacenamiento de carbono en biomasa y suelo en sistemas agroforestales y monocultivos.

Table 8. Carbon storage in biomass and soil in agroforestry systems and monoculture.

\begin{tabular}{|c|c|c|c|c|c|}
\hline \multirow{2}{*}{ Sistemas estudiados } & \multirow{2}{*}{$\begin{array}{l}\text { Principales aspectos } \\
\text { analizados }\end{array}$} & \multicolumn{2}{|c|}{ Resultados } & \multirow{2}{*}{$\begin{array}{c}\text { Respuesta } \\
(+,-,=)\end{array}$} & \multirow{2}{*}{ Referencia } \\
\hline & & En asocio & En monocultivo & & \\
\hline \multirow{2}{*}{$\begin{array}{l}\text { Cacao con sombra (árboles y fruta- } \\
\text { les) vs. monocultivo de cacao. }\end{array}$} & $\begin{array}{l}\text { Fijación carbono } \\
\text { total }\left(\mathrm{Mg} \mathrm{C} \mathrm{ha}^{-1}\right)\end{array}$ & 141,4 & 85,2 & $(+)$ & \multirow{2}{*}{$\begin{array}{l}\text { Jadán et al. } \\
\qquad(2012)\end{array}$} \\
\hline & $\begin{array}{l}\text { Fijación carbono } \\
\text { biomasa total }\left(\mathrm{Mg} \mathrm{C} \mathrm{ha}^{-1}\right)\end{array}$ & 6,8 & 7,6 & $(+)$ & \\
\hline $\begin{array}{l}\text { Cacao asociado con árboles fruta- } \\
\text { les vs. monocultivo cacao }\end{array}$ & $\begin{array}{l}\text { Fijación de carbono } \\
\text { en biomasa total } \\
\left(\mathrm{t} \mathrm{CO}_{2} \mathrm{e} \mathrm{ha}^{-1} \mathrm{año}^{-1}\right)\end{array}$ & 17,7 & 9,4 & $(+)$ & $\begin{array}{l}\text { Marín et al. } \\
\quad(2016)\end{array}$ \\
\hline $\begin{array}{l}\text { Café asociado con nogal cafetero } \\
\text { vs. monocultivo café }\end{array}$ & $\begin{array}{l}\text { Fijación de carbono } \\
\text { en biomasa total } \\
\left(\mathrm{Mg} \mathrm{CO}_{2} \mathrm{e} \mathrm{ha}^{-1} \mathrm{año}^{-1}\right)\end{array}$ & 18,03 & 1,9 & $(+)$ & $\begin{array}{l}\text { Canal Daza y } \\
\text { Andrade (2019) }\end{array}$ \\
\hline $\begin{array}{l}\text { Café asociado con nogal cafetero } \\
\text { vs. monocultivo de café }\end{array}$ & $\begin{array}{l}\text { Fijación de carbono } \\
\text { en biomasa aérea } \\
\left(\mathrm{Mg} \mathrm{ha}^{-1} \mathrm{año}^{-1}\right)\end{array}$ & 4,37 & 0,63 & $(+)$ & $\begin{array}{l}\text { Andrade et al. } \\
\qquad(2014)\end{array}$ \\
\hline $\begin{array}{l}\text { Agroforestal en base a cacao vs. } \\
\text { monocultivo de cacao }\end{array}$ & $\begin{array}{l}\text { Fijación carbono } \\
\text { en suelo }\left(\mathrm{t} \mathrm{ha}^{-1)}\right.\end{array}$ & 37,19 & 37,68 & $(=)$ & $\begin{array}{c}\text { Suxo Hinojosa } \\
\text { y Cruz Choque } \\
(2017) \\
\end{array}$ \\
\hline $\begin{array}{l}\text { Cacao con sombra (árboles y fruta- } \\
\text { les) vs. monocultivo de cacao }\end{array}$ & $\begin{array}{l}\text { Fijación carbono } \\
\text { en suelo }\left(\mathrm{Mg} \mathrm{C} \mathrm{ha}^{-1}\right)\end{array}$ & 69,2 & 74,9 & $(=)$ & $\begin{array}{l}\text { Jadán et al. } \\
\text { (2012) }\end{array}$ \\
\hline
\end{tabular}

Tabla 9. Balance neto de gases de efecto invernadero (GEI) y huella de carbono en sistemas agroforestales de café y monocultivo.

Table 9. Net greenhouse gas balance and carbon footprint in agroforestry systems of coffee and monoculture.

\begin{tabular}{|c|c|c|c|c|c|}
\hline \multirow{2}{*}{ Sistemas estudiados } & \multirow{2}{*}{$\begin{array}{c}\text { Principales aspectos } \\
\text { analizados }\end{array}$} & \multicolumn{2}{|c|}{ Resultados } & \multirow{2}{*}{$\begin{array}{c}\text { Respuesta } \\
(+,-,=)\end{array}$} & \multirow{2}{*}{ Referencia } \\
\hline & & Asocio & Monocultivo & & \\
\hline $\begin{array}{l}\text { Asociación café con Inga vs. } \\
\text { café en monocultivo }\end{array}$ & $\begin{array}{l}\text { Balance neto de GEI } \\
\left(\mathrm{Mg} \mathrm{CO}_{2} \mathrm{e} \mathrm{ha}^{-1} \mathrm{año}^{-1}\right)\end{array}$ & 14,59 & 3,83 & $(+)$ & $\begin{array}{l}\text { Hergoualc'h } \\
\text { et al. (2012) }\end{array}$ \\
\hline $\begin{array}{l}\text { Asociación café con nogal } \\
\text { cafetero vs. monocultivo café }\end{array}$ & $\begin{array}{l}\text { Huella de carbono } \\
\left(\mathrm{Mg} \mathrm{CO}_{2} \mathrm{e} \mathrm{ha}^{-1} \mathrm{año}^{-1}\right)\end{array}$ & 12,8 & $-6,4$ & $(+)$ & $\begin{array}{c}\text { Canal Daza y } \\
\text { Andrade (2019) }\end{array}$ \\
\hline
\end{tabular}

Finalmente, se destaca la importancia del consorcio con especies arbóreas al momento de evaluar la emisión de GEI a nivel parcelario y su evaluación a nivel más global. Investigaciones realizadas en sistemas cafetaleros en Costa Rica y Colombia reflejan un balance neto significativamente superior cuando se implementa una asociación, destacando que en este tipo de arreglo el acopio de gases es sustancialmente mayor que la emisión (Tabla 9). También la bondad de la innovación en café se destaca al momento de medir la huella de carbono que considera la emisión en prácticas agrícolas y actividades de procesamiento del producto, donde el asocio genera resultados positivos y muy por encima que el monocultivo con sello negativo.

\subsubsection{Reducción de plagas, enfermedades y fomento del control biológico}

El uso de la biodiversidad para el manejo de insectos y microorganismos perjudiciales es un aspecto crucial en la agricultura, principalmente porque puede minimizar el uso de agroquímicos al fomentar un control biológico (FAO, 2018). Las investigaciones en los últimos años están mayormente orientadas a evaluar la dinámica de poblaciones de artrópodos mediante el uso de diversidad vegetal, siendo más escasa la literatura sobre el control de enfermedades provocadas por microorganismos como hongos, virus, bacterias y nematodos; probablemente por la tendencia al estudio y uso de microorganismos benéficos para el control de enfermedades fuertemente impulsada en los últimos años (Rivera-Méndez, 2016).

Los principales beneficios de la asociación de cultivos sobre sus componentes individuales en el manejo de plagas y enfermedades son: (i) reducción de insectos nocivos; (ii) mayor presencia de enemigos naturales; y (iii) disminución en población de patógenos que causan enfermedades en las plantas (Tabla 10). Sin embargo, no se puede afirmar que en la totalidad de los casos existen resultados significativos sobre el manejo de 
Tabla 10. Incidencia de plagas en sistemas asociados y monocultivos.

Table 10. Pest incidence in association systems and monoculture.

\begin{tabular}{|c|c|c|c|c|c|}
\hline \multirow{2}{*}{ Sistemas estudiados } & \multirow{2}{*}{ Aspectos analizados } & \multicolumn{2}{|c|}{ Resultados } & \multirow{2}{*}{$\begin{array}{c}\text { Respuesta } \\
(+,-,=)\end{array}$} & \multirow{2}{*}{ Referencia } \\
\hline & & Aso. & Mon. & & \\
\hline \multirow{3}{*}{$\begin{array}{l}\text { Asociación de tomate con maíz } \\
\text { vs. monocultivos de tres } \\
\text { variedades de tomate }\end{array}$} & $\begin{array}{l}\text { Población adulta de mosca blanca } \\
\text { (individuos/hoja) }\end{array}$ & $0,5-0,7$ & $0,9-1,3$ & $(+)$ & \multirow{3}{*}{$\begin{array}{l}\text { León et al. } \\
\qquad(2000)\end{array}$} \\
\hline & $\begin{array}{c}\% \text { de parasitismo } \\
(\text { Diglyphus spp })\end{array}$ & $36,4-0,7$ & $7,86-15$ & $(+)$ & \\
\hline & $\begin{array}{l}\text { Oviposición (unidades foliolo }{ }^{-1} \text { ) } \\
\text { (Chrysopa spp.) }\end{array}$ & $0,4-0,5$ & 0,3 & $(+)$ & \\
\hline \multirow{2}{*}{$\begin{array}{l}\text { Algodón intercalado con varias } \\
\text { especies vs. monocultivo de } \\
\text { algodón }\end{array}$} & $\begin{array}{l}\text { Densidad de insectos adultos } \\
\text { (Orius spp.), (individuos } 30 \mathrm{~m}^{-1} \text { ) }\end{array}$ & 12,3 & 4,5 & $(+)$ & \multirow{2}{*}{$\begin{array}{l}\text { Loya Ramírez } \\
\text { et al. (2003) }\end{array}$} \\
\hline & $\begin{array}{c}\text { Densidad de insectos adultos } \\
\text { (Geocoris spp.) } \\
\text { (individuos } 30 \mathrm{~m}^{-1} \text { ) }\end{array}$ & 32 & 6,8 & $(+)$ & \\
\hline \multirow{2}{*}{$\begin{array}{l}\text { Asociación tomate, pipian y } \\
\text { frijol vs. monocultivo de cada } \\
\text { especie }\end{array}$} & $\begin{array}{c}\text { Población plagas (total) (Bemisa } \\
\text { tabaci, Liriomiza sativae, Empoas- } \\
\text { ca kraemeri, Diabrotica balteata, } \\
\text { Aplhis sp. Melittia sp. } \\
\text { Diaphania nitidalis) }\end{array}$ & 1.186 & 1.166 & $(-)$ & \multirow{2}{*}{$\begin{array}{l}\text { Jiménez } \\
\text { Martínez et al. } \\
\text { (2008) }\end{array}$} \\
\hline & $\begin{array}{c}\text { Población benéficos (total) } \\
\text { Apis Mellifera, varios del orden } \\
\text { Himenóptera (Familia Formicidae } \\
\text { y Arácnidae) }\end{array}$ & 472 & 801 & $(-)$ & \\
\hline $\begin{array}{l}\text { Asociación musas frente a } \\
\text { monocultivo de orito }\end{array}$ & $\begin{array}{l}\text { Población de agente patógeno } \\
\text { (Fusarium oxysporum) }\end{array}$ & 122 & 371 & $(+)$ & Vera (2017) \\
\hline
\end{tabular}

insectos; incluso, pueden reportarse efectos contrarios. Poveda et al. (2008) al realizar una revisión bibliográfica de 62 estudios relacionados con cultivos de ciclo corto y especies hortofrutícolas, identificó que solo en la mitad de casos se obtuvo como resultado el aumento de enemigos naturales y la reducción de plagas. Los factores que pueden influir en el resultado negativo del asocio estarían relacionados con la temporalidad de los componentes vegetales, haciendo necesaria la siembra de especies compañeras antes del establecimiento del cultivo principal o de interés económico (Loya Ramírez et al., 2003); en tanto que el efecto positivo está relacionado con una mayor diversidad de insectos por abundancia de recursos alimenticios, protección por barreras físicas de cultivos acompañantes y efecto trampa de algunas especies (caso plagas), (Altieri y Nicholls, 2000), y de una mayor resistencia otorgada por la diversidad cultivada, inter o intraespecífica (caso enfermedades), (Ochoa Lozano, 2018).

\subsubsection{Incremento de la diversidad biológica, conservación del suelo y optimización del recurso hídrico}

El adecuado manejo de los recursos naturales constituye un aspecto medular para generar alimentos de manera sostenible. Al existir procesos de deterioro del suelo y disminución de la oferta hídrica en áreas agrícolas, la implementación de sistemas asociados puede constituirse en una alternativa adecuada para enfrentar estas adversidades. Las investigaciones desarrolladas en este marco visibilizan las bondades de varios tipos de arreglos al registrar: (i) mayor diversidad biológica en el suelo; (ii) recuperación de tierras degradadas y reducción de procesos erosivos; (iii) aumento de materia orgánica; (iv) incremento de macro y micronutrientes en suelo por asocio con cultivo de leguminosas y especies arbóreas; y (v) mejor eficiencia en el uso del agua y de la radiación solar (Figura 9).

Finalmente, se destaca la importancia que tiene la biodiversidad para enfrentar procesos erosivos provocados por el agua. Investigaciones realizadas en sistemas agroforestales de café en México, determinaron que el estrato más importante para reducir la erosión hídrica estaría en el componente arbustivo y mantillo (hojarasca y residuos sobre la superficie del suelo), gracias a la dispersión de la energía de la lluvia y disminución del escurrimiento superficial (Pérez Nieto et al., 2012). 


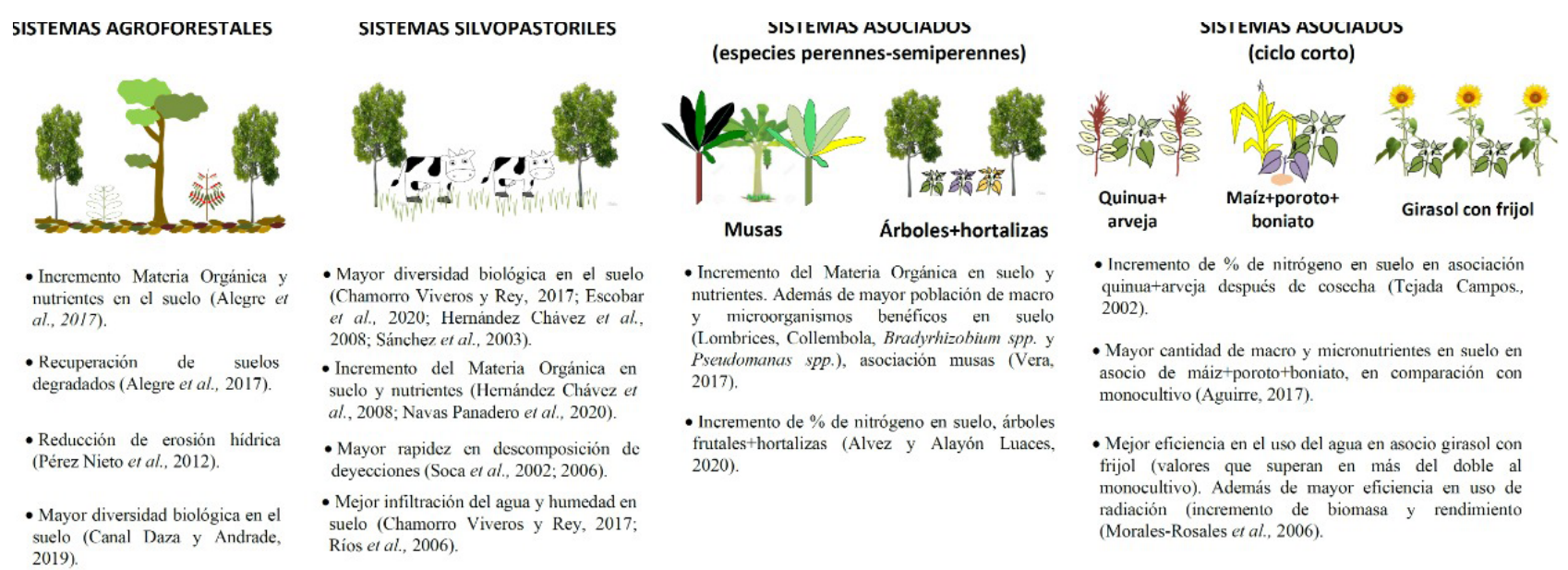

Figura 9. Ventajas de sistemas asociados en relación con las propiedades del suelo y el uso de recursos naturales.

Figure 9. Advantages of association systems in soil properties and natural resources use.

\section{Conclusiones}

La combinación de especies vegetales constituye una práctica implementada desde épocas prehispánicas; sin embargo, ha sufrido un progresivo quebranto por el impulso de la lógica del monocultivo en el campo. A pesar de esto, en la actualidad es posible identificar su siembra en territorios rurales con énfasis en sistemas productivos campesinos. Su implementación puede ser realizada considerando diversas orientaciones productivas con baseen a especies de ciclo corto, perenne, cultivos hortofrutícolas, pasturas, árboles, arbustos; e incluso incorporando crianzas mayores.

La asociación de cultivos constituye una alternativa viable para alcanzar una agricultura sustentable. Los principales beneficios están relacionados con mejor uso de los recursos naturales (agua, suelo y energía solar), aumento de producción, incremento de ingresos agropecuarios, mitigación del cambio climático por mayor capacidad de almacenamiento de carbono, manejo ecológico de plagas y enfermedades, mejoramiento del bienestar animal, gestión natural de la fertilidad del suelo y acrecentamiento de la biodiversidad de macro y microorganismos existentes en un agroecosistema.

A pesar de existir un avance significativo en el tema, es preciso ampliar las investigaciones considerando el amplio abanico de especies de interés económico existentes en América Latina y el Caribe; además de evidenciar los resultados de una manera integral, considerando aspectos económicos, productivos, socioculturales y ambientales.

\section{Agradecimientos}

Un cordial agradecimiento al Dr. José Benjamín Ochoa Lozano por los comentarios emitidos a fin de enriquecer el presente artículo.

\section{Contribuciones de los autores}

- Christian Vicente Tamayo Ortiz: Conceptualización, Metodología, Investigación, Redacción-borrador original.

- Julio Cesar Alegre Orihuela: Redacción-revisión y edición, Supervisión, Validación.

\section{Referencias}

Aguilar, J., Illsley, C., y Marielle, C. (2003). Los sistemas agrícolas de maíz y sus procesos técnicos. En G. Esteva, y C. Marielle (coords.), Sin maiz no hay país (pp. 83-122). Consejo Nacional para la Cultura y las Artes. 
Aguirre, S. (2017). Policultivos y silvopastoreo como estrategias agroecológicas de productores familiares en Colonia Gestido. Universidad de Antioquia. https://bibliotecadigital.udea.edu.co/handle/10495/8887

Alegre Orihuela, J. (2015). Sistema agroforestal multiestrato. Recuperación de suelos degradados en la Amazonía. LEISA Revista de Agroecología, 31(1), 28-30. https://www.leisa-al.org/web/index.php/ volumen-31-numero-1/1091-sistema-agroforestal-multiestrato-recuperacion-de-suelos-degradados-en-la-amazonia

Alegre, J. (2017). La Agroforestería en la Amazonía Peruana para recuperar suelos degradados y mitigar efectos de Cambio Climático. XVI Congreso Nacional y VII Internacional de la Ciencia del Suelo "Crianza del suelo para el buen vivir". Ayacucho.

Alegre, J., Lao, C., Silva, C., y Schrevens, E. (2017). Recovering degraded lands in the Peruvian Amazon by cover crops and sustainable agroforestry systems. Peruvian Journal of Agronomy, 1(1), 1-7. http://dx.doi. org/10.21704/pja.v1i1.1005

Altieri, M. (2002). Agroecología: Principios y estrategias para diseñar sistemas agrarios sustentables. En S. J. Sarandón (ed.), Agroecología: El camino hacia una agricultura sustentable (pp. 49-56). Ediciones Científicas Americanas.

Altieri, M., y Nicholls, C. (2000). Biodiversidad y manejo de plagas en agroecosistemas. En Teoría y práctica para una agricultura sustentable (1a ed.) (pp. 167-180). Programa de las Naciones Unidas para el Medio Ambiente [PNUMA]. http://www.agro.unc.edu.ar/ biblio/AGROECOLOGIA2\%5B1\%5D.pdf

Alvez, N. V., y Alayón Luaces, P. (2020). Evaluación de policultivos frutihortícolas agroecológicos del Nordeste Argentino. Boletín de la Sociedad Argentina de Botánica, 55(2), 273-284. https://doi. org/10.31055/1851.2372.v55.n2.26899

Andrade, H. J., Marín, L. M., y Pachón, D. P. (2014). Fijación de carbono y porcentaje de sombra en sistemas de producción de café (Coffea arabica L.) en el Líbano, Tolima, Colombia. Bioagro. 26(2), 127-132. http://ve.scielo.org/scielo.php?script=sci_arttext\&pid=S1316-33612014000200008\&lng=es\&nrm=iso

Barros Júnior, A. P., Rezende, B. L. A., Cecílio Filho, A. B., Martins, M. I. E. G., y Pôrto, D. R. Q. (2008). Custo de produção e rentabilidade de alface crespa e americana em monocultura e quando consorciada com rúcula. Revista Caatinga, 21(2), 181-192. https://periodicos.ufersa.edu.br/index. $\mathrm{php} /$ caatinga/article/view/710

Canal Daza, D. S., y Andrade, H. J. (2019). Sinergias mitigación-adaptación al cambio climático en sistemas de producción de café (Coffea arabica), de Tolima, Colombia. Revista de Biología Tropical, 67(1), 36-46. https://dx.doi.org/10.15517/rbt.v67i1.32537

Caycho-Ronco, J., Arias-Mesia, A., Oswald, A., Esprella-Elias, R., Rivera, A., Yumisaca, F., y Andrade-Piedra, J. (2009). Tecnologías sostenibles y su uso en la producción de papa en la región altoandina. Revista Latinoamericana de la Papa, 15(1), 20-37. https://doi.org/10.37066/ralap.v15i1.149

Cecílio Filho, A. B., y May, A. (2002). Produtividade das culturas de alface e rabanete em função da época de estabelecimento do consórcio. Horticultura Brasileira, 20(3), 501-504. https://dx.doi.org/10.1590/ S0102-05362002000300021

Cecílio Filho, A. B., Rezende, B. L. A., y Canato, G. H. D. (2007). Produtividade de alface e rabanete em cultivo consorciado estabelecido em diferentes épocas e espaçamentos entre linhas. Horticultura Brasileira, 25(1), 15-19. https://dx.doi.org/10.1590/S0102-05362007000100004

Chamorro Viveros, D., y Rey, A. M. (2017). Los sistemas silvopasoriles como estrategia de ganadería ecológica y productiva en Colombia. En A. Fernández Mayer (ed.), Producción de carne y leche bovina en sistemas silvopastoriles (pp. 52-54). Ediciones Instituto Nacional de Tecnología Agropecuaria. https:// repositorio.inta.gob.ar/xmlui/handle/20.500.12123/7668

Chará, J., Reyes, E., Peri, P., Otte, J., Arce, E., y Schneider, F. (2018). Sistemas silvopastoriles y su contribución al uso eficiente de los recursos y los Objetivos de Desarrollo Sostenible: Evidencia desde América Latina. Organización de las Naciones Unidas para la alimentación y la Agricultura [FAO], Centro para la Investigación en Sistemas Sostenibles de Producción Agropecuaria [CIPAV], y Agri Benchmark. http:// www.fao.org/publications/card/es/c/CA2792ES/

Chará, J., Rivera, J., Barahona, R., Murgueitio R., E., Deblitz, C., Reyes, E., Martins Mauricio, R., Molina, J. J., Flores, M., y Zuluaga, A. (2017). Intensive Silvopastoral Systems: Economics and Contribution to Climate Change Mitigation and Public Policies. En F. Montagnini (ed.), Integrating Landscapes: Agroforestry for Biodiversity Conservation and Food Sovereignty (pp. 395-416). Advances in Agroforestry, vol 12. Springer, Cham. https://doi.org/10.1007/978-3-319-69371-2_16 
Chargoy Zamora, C. I. (2004). La medición agronómica de la eficiencia en el rendimiento de los cultivos múltiples. En. J. L. Chávez-Servia, J. Tuxill, y D. I. Jarvis (eds), Manejo de la diversidad de los cultivos en los agroecosistemas tradicionales (pp. 110-117). Instituto Internacional de Recursos Fitogenéticos.

Corral, R., Duicela, L., y Maza, H. (2006). Fijación y almacenamiento de carbono en sistemas agroforestales con café arábigo y cacao, en dos zonas agroecológicas del litoral ecuatoriano. X Congreso Ecuatoriano de la Ciencias del Suelo. Ecuador.

Ebel, R., Pozas Cárdenas, J. G., Soria Miranda, F., y Cruz González, J. (2017). Manejo orgánico de la milpa: rendimiento de maíz. frijol y calabaza en monocultivo y policultivo. Terra Latinoamericana, 35(2), 149160. https://doi.org/10.28940/terra.v35i2.166

Escobar, M. I., Navas Panadero, A., Medina, C. A., Corrales-Álvarez, J. D., Tenjo, A. I., y Borrás-Sandoval, L. M. (2020). Efecto de prácticas agroecológicas sobre características del suelo en un sistema de lechería especializada del trópico alto colombiano. Livestock Research for Rural Development, 32(40), 58. http:// www.lrrd.org/lrrd32/4/maria.es32058.html

Gómez Betancur, L. M., Márquez Girón, S. M., y Restrepo Betancur, L. F. (2018). La milpa como alternativa de conversión agroecológica de sistemas agrícolas convencionales de frijol (Phaseolus vulgaris), en el municipio El Carmen de Viboral, Colombia. Idesia (Arica), 36(1), 123-131. https://dx.doi.org/10.4067/ S0718-34292018000100123

Grupo Intergubernamental de Expertos sobre el Cambio Climático [IPCC]. (2013). Cambio Climático 2013. Bases fisicas. Resumen para responsables de politicas, Resumen técnicos y Preguntas frecuentes. OMM, PNUMA. https://www.ipcc.ch/site/assets/uploads/2018/03/WG1AR5_SummaryVolume_FINAL_SPANISH.pdf

Gutiérrez-Martínez, A., Aguilar-Jiménez, C. E., Galdamez-Galdamez, J., Mendoza-Pérez, S., y Martínez-Aguilar, F. B. (2007). Impacto socioeconómico de los sistemas de cultivos maiz-frijol-calabaza en la Frailesca, Chiapas, México. I Seminario de Cooperación y Desarrollo en Espacios Rurales Iberoamericanos Sostenibles e Indicadores. Almería.

Hergoualc'h, K., Blanchart, E., Skiba, U., Hénault, C., y Harmand, J. M. (2012). Changes in carbon stock and greenhouse gas balance in a coffee (Coffea arabica) monoculture versus an agroforestry system with Inga densiflora, in Costa Rica. Agriculture, Ecosystems and Environment, 148, 102-110. https://doi.org/10.1016/j.agee.2011.11.018

Hernández Chávez, M., Sánchez Cárdenas, S., y Simón Guelmes, L. (2008). Efecto de los sistemas silvopastoriles en la fertilidad edáfica. Zootecnia Tropical, 26(3), 319-321. http://ve.scielo.org/scielo.php?script=sci_arttext\&pid=S0798-72692008000300035

Hernández Rodríguez, R., y Ponce Ceballo, P. (2004). Efecto del silvopastoreo como sistema sostenible de explotación bovina sobre la composición de la leche. Livestock Research for Rural Development, 16(6),43. http://www.lrrd.org//rrd16/6/hern16043.htm

Jacobsen, S. E., y Sherwood, S. (2002). Cultivo de granos andinos en Ecuador. Informe sobre los rubros quinua, chocho y amaranto. Ediciones Abya-Yala, Organización de las Naciones Unidas para la Agricultura y la Alimentación [FAO], Centro Internacional de la Papa [CIP], y Catholic Relief Services [CRS].

Jadán, O., Torres, B., y Günter, S. (2012). Influencia del uso de la tierra sobre almacenamiento de carbono en sistemas productivos y bosque primario en Napo, Reserva de Biosfera Sumaco, Ecuador. Revista Amazónica: Ciencia y Tecnología, 1(3), 173-186. https://www.uea.edu.ec/wp-content/uploads/2018/07/influencia-tierra-almacenamiento-carbono-sistemas-productivos-revista-cientifica-articulo-2-vol-1-N-3.pdf

Jiménez Martínez, E., Sandino, V., Pérez, D., y Sánchez, D. (2008). Comparación de la incidencia poblacional de insectos plagas y benéficos en arreglos de monocultivo versus policultivos de tomate (Lycopersicum esculentum MILL,) Pipian (Cucurbita pepo L.) y frijol (Phaseolus vulgaris L.). La Calera, 8(9), 5-11.

Le Gall, A. (2007). Conservación del bosque seco e intensificación agropecuaria en Cazaderos: ¿Se inclinará la balanza?. En M. Vaillant, D. Cepeda, P. Gondard, A. Zapatta, y A. Meunier (eds.), Mosaico Agrario. Diversidades y antagonismos socioeconómicos en el campo ecuatoriano (pp. 125-152). SIPAE, IRD, IFEA. https://biblio.flacsoandes.edu.ec/libros/digital/42000.pdf

León, A., Pino, M. de los A., González, C., y del Pozo, E. (2000). Evaluación comparativa de densidades de fitófagos y enemigos naturales en policultivo tomate-maíz. Cultivos Tropicales, 21(1), 53-60. https://www. redalyc.org/articulo.oa?id=193232232010

Liebman, M. (1999). Sistemas de policultivos. En M. A. Altieri (ed.), Agroecología: Bases cientificas para una agricultura sustentable (pp. 191-202). Editorial Nordan-Comunidad. http://agroeco.org/wp-content/ uploads/2010/10/Libro-Agroecologia.pdf 
Loya Ramírez, J. G., García Hernández, J. L., Ellington, J. J., y Thompson, D. V. (2003). Impacto de la asociación de cultivos en la densidad de insectos hemípteros entomófagos. Interciencia, 28(7), 415-420. https:// www.redalyc.org/pdf/339/33908208.pdf

Loyola Illescas, J. (2016). Conocimientos y prácticas ancestrales y tradicionales fortalecen la sustentabilidad de los sistemas hortícolas de la parroquia San Joaquín. La Granja: Revista de Ciencias de la Vida, 24(2), 29-42. http://dx.doi.org/10.17163/lgr.n24.2016.03

Mahecha, L. (2003). Importancia de los sistemas silvopastoriles y principales limitantes para su implementación en la ganadería colombiana. Revista Colombiana de Ciencias Pecuarias, 16(1), 11-18. https:// revistas.udea.edu.co/index.php/rccp/article/view/323847

Maignan, S., y Nicolalde, V. (2007). Límites de la intensificación agropecuaria en un contexto de mercado inestable: El caso de la cuenca baja del río Portoviejo. En M. Vaillant, D. Cepeda, P. Gondard, A. Zapatta, y A. Meunier (eds.), Mosaico Agrario. Diversidades y antagonismos socioeconómicos en el campo ecuatoriano (pp. 203-224). SIPAE, IRD, IFEA. https://biblio.flacsoandes.edu.ec/libros/digital/42000.pdf

Marín Q., M. del P., Andrade, H. J., y Sandoval, A. P. (2016). Fijación de carbono atmosférico en la biomasa total de sistemas de producción de cacao en el departamento del Tolima, Colombia. Revista U.D.C.A Actualidad \& Divulgación Cientifica, 19(2), 351-360. https://doi.org/10.31910/rudca.v19.n2.2016.89

Martínez Martín, A. F., y Manrique Corredor, E. J. (2014). Alimentación prehispánica y transformaciones tras la conquista europea del altiplano cundiboyacense, Colombia. Revista Virtual Universidad Católica del Norte, 1(41), 96-111. https://revistavirtual.ucn.edu.co/index.php/RevistaUCN/article/view/468

Masuhara, A., Valdés, E., Pérez, J., Gutiérrez, D., Vásquez, J. C., Salcedo, E., Juárez, M. de J., y Merino, A. (2015). Carbono almacenado en diferentes sistemas afroforestales de café en Huatusco, Veracruz, México. Revista Amazónica Ciencia y Tecnología, 4(1), 66-93. https://www.uea.edu.ec/revistas/index.php/ revistaamazonica/article/view/148

Mazoyer, M., y Roudart, L. (2006). A history of world agriculture: from the neolithic age to the current crisis. Earthscan.

Molina-Anzures, M. F., Chavez-Servia, J. L., Gil-Muñoz, A., López, P. A., Hernández-Romero, E., y Ortiz-Torres, E. (2016). Eficiencias productivas de asociaciones de maíz, frijol y calabaza (Curcubita pepo L.), intercaladas con árboles frutales. Phyton, International Journal of Experimental Botany, 85, 36-50. http:// www.revistaphyton.fund-romuloraggio.org.ar/vol85/Molina_Anzures.pdf

Morales-Rosales, E. J., Escalante-Estrada, J. A., Tijerina-Chávez, L., Volke-Haller, V. y Sosa-Montes, E. (2006). Biomasa, rendimiento, eficiencia en el uso del agua y de la radiación solar del agrosistema girasol-frijol. Terra Latinoamericana, 24(1), 55-64. https://www.redalyc.org/articulo.oa?id=57311494007

Murgueitio, E., y Giraldo C., C. (2009). Sistemas silvopastoriles y el control de parásitos. Carta Fedegan, (115), 60-63. https://www.fedegan.org.co/carta-fedegan-115-la-fertilidad-es-la-clave

Navas Panadero, A. (2010). Importancia de los sistemas silvopastoriles en la reducción del estrés calórico en sistemas de producción ganadera tropical. Revista de Medicina Veterinaria, (19), 113-122. https://doi. org/10.19052/mv.782

Navas Panadero, A., Aragón Henao, L. F., y Triana Valenzuela, J. F. (2020). Efecto del componente arbóreo sobre la dinámica de crecimiento y calidad nutricional de una pradera mixta en trópico alto. Revista de Medicina Veterinaria, 1(41), 71-82. https://doi.org/10.19052/mv.vol1.iss41.7

Obispo, N. E., Espinoza, Y., Gil, J. L., Ovalles, F., y Rodríguez, M. F. (2008). Efecto del sombreado sobre la producción y calidad del pasto guinea (Panicum maximun) en un sistema silvopastoril. Zootecnia Tropical, 26(3), 285-288. http://ve.scielo.org/scielo.php?script=sci_arttext\&pid=S0798-72692008000300027\&ln$\mathrm{g}=\mathrm{es} \& \mathrm{nrm}=\mathrm{iso}$

Ochoa Lozano, J. B. (2018). Farmer crop variety mixtures to cope with disease epidemics in the common bean cropping system of the Ecuadorian highlands. Sapienza Universitá di Roma. https://iris.uniroma1. it/handle/11573/1077355

Oliva, M., Valqui, L., Meléndez, J., Milla, M., Leiva, S., Collazos, R., y Maicelo, J. L. (2018). Influencia de especies arbóreas nativas en sistemas silvopastoriles sobre el rendimiento y valor nutricional de Lolium multiflorum y Trifolium repens. Scientia Agropecuaria, 9(4), 579- 583. https://dx.doi.org/10.17268/sci. agropecu.2018.04.14

Oliveira, E. Q. de, Bezerra Neto, F., Negreiros, M. Z. de, y Barros Júnior, A. P. (2004). Desempenho agroeconômico do bicultivo de alface em sistema solteiro e consorciado com cenoura. Horticultura Brasileira, 22(4), 712-717. https://dx.doi.org/10.1590/S0102-05362004000400009 
Ordóñez Jurado, H. R., Navia Estrada, J. F., y Ballesteros Possú, W. (2018). Tipificación de sistemas de producción de café en La Unión Nariño, Colombia. Temas agrarios, 24(1), 53-65. https://doi.org/10.21897/rta.v24i1.1779

Organización de las Naciones Unidas para la alimentación y la Agricultura [FAO]. (2018). Agricultura Sostenible y Biodiversidad. Un vínculo indisociable. FAO. http://www.fao.org/3/i6602s/i6602s.pdf

Organización de las Naciones Unidas para la alimentación y la Agricultura [FAO], Fondo Internacional de Desarrollo Agrícola [FIDA], Organización Mundial de la Salud [OMS], Programa Mundial de Alimentos [PMA], y Fondo de las Naciones Unidas para la Infancia [UNICEF]. (2017). El estado de la seguridad alimentaria y la nutrición en el mundo 2017. Fomentando la resiliencia en aras de la paz y la seguridad alimentaria. FAO. http://www.fao.org/3/I7695s/I7695s.pdf

Organización Internacional del Trabajo [OIT]. (2017). Objetivos de Desarrollo Sostenible: Manual de referencia Sindical sobre la Agenda 2030 para el Desarrollo Sostenible. https://www.ilo.org/

Osorio-Espinoza, H., Leyva-Galan, A., y Toledo-Toledo, E. (2017). Evaluación de cultivos de ciclo corto en Rambután (Nephelium lappaceum L.) en México utilizando IET. Cultivos tropicales, 38(3), 7-13.

Palm, C. A., Alegre, J. C., Arevalo, L., Mutuo, P. K., Mosier, A. R., y Coe, R. (2002). Nitrous oxide and methane fluxes in six different land use systems in the Peruvian Amazon. Global Biogeochemical Cycles, 16(4), 1073. https://doi.org/10.1029/2001GB001855

Peralta, E. (2016). El chocho en Ecuador "estado del Arte”. INIAP, PRONALEG. https://repositorio.iniap. gob.ec/handle/41000/3938

Pérez Nieto, J., Valdés Velarde, E., y Ordaz Chaparro, V. M. (2012). Cobertura vegetal y erosión del suelo en sistemas agroforestales de café bajo sombra. Terra Latinoamericana, 30(3), 249-259. https://www. redalyc.org/articulo.oa?id $=57325509001$

Pino, M. (2001). Modificación de la productividad del cultivo del tomate (Lycopersicon esculentum Mill) fuera del periodo óptimo utilizando el maíz como sombra natural. Instituto Nacional de Ciencias Agrícolas. http://repositorio.geotech.cu/jspui/bitstream/1234/2814/1/Modificaci\%C3\%B3n\%20\%20productividad\%20tomate.\%20MAPino.pdf

Pocomucha, V. S., Alegre, J., y Abregú, L. (2016) Análisis socioeconómico y carbono almacenado en sistemas agroforestales de cacao (Theobroma cacao L.) en Huánuco. Ecología Aplicada, 15(2), 107-114. https:// dx.doi.org/10.21704/rea.v15i2.750

Poveda, K., Gómez, M. I., y Martínez, E. (2008). Diversification practices: their effect on pest regulation and production. Revista Colombiana de Entomología, 34(2), 131-144. http://www.scielo.unal.edu.co/pdf/ $\mathrm{rcen} / \mathrm{v} 34 \mathrm{n} 2 / \mathrm{v} 34 \mathrm{n} 2 \mathrm{a} 01 . \mathrm{pdf}$

Poveda, V., Orozco, L., Medina, C., Cerda, R., y López, A. (2013). Almacenamiento de carbono en sistemas agroforestales de cacao en Waslala, Nicaragua. Agroforestería en las Américas, 49, 42-50. https://repositorio.catie.ac.cr/handle/11554/5760

Reyes, E., Bellagamba, A., Molina, J. J., Izquierdo, L., Deblitz, C., Chará, J., Mitchell, L., Romanowicz, B., Gómez, M., y Murgueitio, E. (2017). Briefing paper 17/2. Measuring sustainability on cattle ranches Silvopastoral systems. Agri benchmark. http://www.agribenchmark.org/fileadmin/Dateiablage/B-Beefand-Sheep/Reports-Abstracts/ReportSPS6-Colombiancasestudies.pdf

Rezende, B. L. A., Barros Júnior, A. P., Cecílio Filho, A. B., Pôrto, D. R. Q., y Martins, M.I. E.G. (2009). Custo de produção e rentabilidade das culturas de alface, rabanete, rúcula e repolho em cultivo solteiro e consorciadas com pimentão. Ciência e Agrotecnologia, 33(1), 305-312. https://doi.org/10.1590/S141370542009000100042

Rezende, B. L. A., Cecílio Filho, A. B., Martins, M. I. E. G., Costa, C. C., y Feltrim, A. L. (2005). Viabilidade econômica das culturas de pimentão, repolho, alface, rabanete e rúcula em cultivo consorciado, na primavera-verão, Jabotical, estado de São Paulo. Informações Econômicas, SP, 35(3), 22-37. http://www.iea. sp.gov.br/OUT/publicacoes/pdf/tec3-0305.pdf

Ríos, N., Cárdenas, A. Y., Andrade, H. J., Ibrahim, M., Jiménez, F., Sancho, F., Ramírez, E., Reyes, B., y Woo, A. (2006). Escorrentía superficial e infiltración en sistemas ganaderos convencionales y silvopastoriles en el trópico subhúmedo de Nicaragua y Costa Rica. Agroforestería en las Américas, 45, 66-71. https://repositorio.bibliotecaorton.catie.ac.cr/bitstream/handle/11554/7739/Escorrent\%EDa_superficial.pdf?sequence $=2$

Rivera Herrera, J. E., Cuartas, C. A., Naranjo, J. F., Tafur, O., Arenas, F., Uribe, F., Chará, J. D., y Murgueitio R., E. (2012). Calidad y cantidad de leche bovina producida bajo sistemas silvopastoriles intensivos (SSpi) en Colombia. IV Congreso Internacional sobre Sistemas Silvopastoriles Intensivos. https://www. researchgate.net/publication/279449075 
Rivera, J. E., Arenas, F. A., Cuartas, C. A., Naranjo, J. F., Tafur Arango, O., Hurtado, E., Gacharna, N., Zambrano, F., y Murgueitio Restrepo, E. (2011). Producción y calidad de leche bovina en un sistema de pastoreo en monocultivo y un sistema silvopastoril intensivo (SSPi) compuesto de Tithonia diversifolia bajo ramoneo directo, Brachiaria spp. y árboles maderables en el piedemonte amazónico. Revista Colombiana de Ciencias Pecuarias, 24(3), 524. https://revistas.udea.edu.co/index.php/rccp/article/view/324710

Rivera, J. E., Cuartas, C. A., Naranjo, J. F., Tafur, O., Hurtado, E. A., Arenas, F. A., Chará, J., y Murgueitio, E. (2015). Efecto de la oferta y el consumo de Tithonia diversifolia en un sistema silvopastoril intensivo (SSPi), en la calidad y productividad de leche bovina en el piedemonte Amazónico colombiano. Livestock Research for Rural Development, 27(10), 189. http://www.lrrd.org//rrd27/10/rive27189.html

Rivera-Méndez, W. (2016). Control microbiológico como experiencia de sostenibilidad local en la agricultura centroamericana. Tecnología en marcha, (Edición Especial Biocontrol), 31-40. https://doi. org/10.18845/tm.v29i7.2703

Romero Delgado, G., Echevarría Rojas, M., Trillo Zárate, F., Hidalgo Lozano, V., Aguirre Terrazas, L., Robles Rodríguez, R., y Núñez Delgado, J. (2020). Efecto del faique (Acacia macracantha) sobre el valor nutricional del pasto guinea (Panicum maximum Jacq.) en un sistema silvopastoril. Revista de Investigaciones Veterinarias del Perú, 31(1), e17562. https://doi.org/10.15381/rivep.v31i1.17562

Salgado, A. S., Guerra, J. G. M., Almeida, D. L., Ribeiro, R. L. D., Espindola, J. A. A., y Salgado, J. A. A. (2006). Consórcios alface-cenoura e alface-rabanete sob manejo orgânico. Pesquisa Agropecuária Brasileira, 41(7), 1141-1147. https://dx.doi.org/10.1590/S0100-204X2006000700010

Salgado-Mora, M. G., Ruiz-Bello, C., Moreno-Martínez, J. L., Irena-Martínez, B., y Aguirre-Medina, J. F. (2018). Captura de carbono en biomasa aérea de árboles de sombra asociados a Coffea arabica L. en el Soconusco Chiapas, México. Agroproductividad, 11(2), 120-126. https://revista-agroproductividad.org/ index.php/agroproductividad/article/view/136

Sánchez, S., Hernández, M., y Simón, L. (2003). Efecto del sistema silvopastoril en la fertilidad edáfica en unidades lecheras de la empresa Nazareno. Pastos y Forrajes, 26(2), 131-136. https://payfo.ihatuey.cu/ index.php?journal $=$ pasto $\&$ page $=$ article \&op $=$ view $\&$ path $\% 5 \mathrm{~B} \% 5 \mathrm{D}=835$

Sarandón, S. J. (2002). La Agricultura como actividad transformadora del ambiente. El Impacto de la Agricultura intensiva de la Revolución Verde. En S. J. Sarandón (ed.), Agroecología: El camino hacia una agricultura sustentable (pp. 23-47). Ediciones Científicas Americanas.

Sarandón, S. J., y Labrador, J. (2002). El uso de policultivos en una agricultura sustentable. En S. J. Sarandón (ed.), Agroecología: El camino hacia una agricultura sustentable (pp. 189-222). Ediciones Científicas Americanas.

Silva, G. S., Rezende, B. L. A., Cecílio Filho, A. B., Barros Júnior, A. P., Martins, M. I. E. G., y Porto, D. R. Q. (2008). Viabilidade econômica do cultivo da alface crespa em monocultura e em consórcio com pepino. Ciência e Agrotecnologia, 32(5), 1516-1523. https://dx.doi.org/10.1590/S1413-70542008000500024

Silva-Laya, S. J., Pérez-Martínez, S., y Ríos-Osorio, L. A. (2016). Evaluación agroecológica de sistemas hortícolas de dos zonas del oriente antioqueño, Colombia. Revista Colombiana de Ciencias Hortícolas, 10(2), 355-366. http://dx.doi.org/10.17584/rcch.2016v10i2.5752

Soca, M., Simón, L., Roque, E., Soca, M., y García, D. E. (2006). Influencia de la macrofauna edáfica en la desaparicion de las excretas en un sistema silvopastoril. Pastos y Forrajes, 29(2), 169. https:/www.redalyc.org/articulo.oa?id=269121704005

Soca, M., Simón, L., Sánchez, S., y Gomez, E. (2002). Dinámica parasitológica en bostas de bovinos bajo condiciones silvopastoriles. Agroforestería de las Américas, 9(33-34), 38-42. https://repositorio.bibliotecaorton.catie.ac.cr/handle/11554/6052

Suxo Hinojosa, F. E., y Cruz Choque, D. (2017). Estimación de biomasa subterránea y carbono en los sistemas de producción; orgánica y monocultivo de cacao (Theobroma cacao L.) en la zona de Alto Beni, Bolivia. Apthapi, 3(3), 718-732. http://ojs.agro.umsa.bo/index.php/ATP/article/view/167

Tamayo, C. (2015). Análisis de las economías campesinas en la acequia Mocha-Huachi. Universidad Central del Ecuador. http://www.dspace.uce.edu.ec/handle/25000/7966

Tejada Campos, T. N. (2002). Estudio de asociaciones de quinua (Chenopodium quinoa Willd.) y Kiwicha (Amaranthus caudatus L.), con lenteja (Lens culinaris L.), haba (Vicia faba L.) y arveja (Pisum sativum L.) en la sierra norte del Perú. Universidad Católica de Temuco.

Urbano, D., Dávila, C., y Moreno, P. (2006). Efecto de las leguminosas arbóreas y la suplementación con concentrado sobre la producción de leche y cambio de peso en vacas doble propósito. Zootecnia Tropical, 24(1), 6983. http://ve.scielo.org/scielo.php?script=sci_arttext\&pid=S0798-72692006000100006\&lng=es\&nrm=iso 
Vargas, E. M. (2011). Cambio climático y crisis alimentaria. Perspectivas, 27, 147-160. https://www.redalyc. org/pdf/4259/425941231009.pdf

Vásquez González, A. Y., Chávez Mejía, C., Herrera Tapia, F., y Carreño Meléndez, F. (2018). Milpa y seguridad alimentaria: El caso de San Pedro El alto, México. Revista de Ciencias Sociales, 24(2), 24-36. https:// doi.org/10.31876/rcs.v24i2.24817

Vega Orozco, G., Ordoñez Espinoza, C. M., Suarez Salazar, J. C., y López Pantoja, C. F. (2014). Almacenamiento de carbono en arreglos agroforestales asociados con café (Coffea arabica) en el sur de Colombia. Revista de Investigación Agraria y Ambiental, 5(1), 213-221. https://doi.org/10.22490/21456453.956

Vera, D. (2017). Biodiversidad intraespecifica varietal para mejorar ambientes degradados por monocultivos en Musáceas, como medida de control de plagas y enfermedades. Universidad Autónoma de Barcelona. https://www.tesisenred.net/handle/10803/457711

\section{Anexo. Especies mencionadas en el documento}

\begin{tabular}{ll}
\hline Cultivo & Nombre científico \\
\hline Algodonero & Gossypium hirsutum \\
Aliso & Alnus acuminata \\
Arveja & Pisum sativum \\
Boniato & Ipomoea batatas \\
Botón de oro & Tithonia diversifolia \\
Calabaza & Cucurbita pepo \\
Cebolla & Allium cepa \\
Cacao & Theobroma cacao \\
Café & Coffea arabica \\
Fréjol-frijol & Phaseolus vulgaris \\
Inga & Inga densiflora \\
Kikuyo & Pennisetum clandestinum \\
Lechuga & Lactuca sativa \\
Leucaena & Leucaena lecucocephala \\
Maíz & Zea mays \\
Matarratón & Gliricidia sepium \\
Pasto estrella & Cynodon nlemfuensis \\
Nogal cafetero & Cordia alliodora \\
Orito & Musa Acuminata AA \\
Pepino & Cucumis sativus \\
Pimiento & Capsicum annuum \\
Pipian & Curcurbita pepo \\
Poroto tape & Vigna unguiculata \\
Quinua & Chenopodium quinoa \\
Rábano, rabanito & Eruca sativa) \\
Rambutan & \\
Rúcula & \\
Zomate & Danahoricon esculentum Mill \\
\hline & \\
\hline
\end{tabular}

